\title{
Evidence of Coronavirus (CoV) Pathogenesis and Emerging Pathogen SARS-CoV-2 in the Nervous System: A Review on Neurological Impairments and Manifestations
}

\author{
Niraj Kumar Jha ${ }^{1}$. Shreesh Ojha ${ }^{2}$. Saurabh Kumar Jha ${ }^{1} \cdot$ Harish Dureja ${ }^{3}$. Sachin Kumar Singh ${ }^{4}$ - Shakti D. Shukla ${ }^{5}$. \\ Dinesh Kumar Chellappan ${ }^{6}$. Gaurav Gupta ${ }^{7}$. Shanu Bhardwaj ${ }^{8}$. Neeraj Kumar ${ }^{9}$. Madhan Jeyaraman ${ }^{10}$. \\ Rashmi Jain ${ }^{11}$. Sathish Muthu ${ }^{12}$. Rohan Kar ${ }^{13}$. Dhruv Kumar ${ }^{14}$. Vineet Kumar Goswami ${ }^{15}$. Janne Ruokolainen ${ }^{16}$. \\ Kavindra Kumar Kesari ${ }^{16} \cdot$ Sandeep Kumar Singh ${ }^{17,18} \cdot$ Kamal Dua $^{5,19,20}$
}

Received: 3 September 2020 / Accepted: 27 November 2020 / Published online: 19 January 2021

(c) The Author(s), under exclusive licence to Springer Science+Business Media, LLC part of Springer Nature 2021

\begin{abstract}
The coronavirus disease 2019 (COVID-19) pandemic is an issue of global significance that has taken the lives of many across the world. Severe acute respiratory syndrome coronavirus 2 (SARS-CoV-2) is the virus responsible for its pathogenesis. The pulmonary manifestations of COVID-19 have been well described in the literature. Initially, it was thought to be limited to the respiratory system; however, we now recognize that COVID-19 also affects several other organs, including the nervous system. Two similar human coronaviruses (CoV) that cause severe acute respiratory syndrome (SARS-CoV-1) and Middle East respiratory syndrome (MERS-CoV) are also known to cause disease in the nervous system. The neurological manifestations of SARS-CoV-2 infection are growing rapidly, as evidenced by several reports. There are several mechanisms responsible for such manifestations in the nervous system. For instance, post-infectious immune-mediated processes, direct virus infection of the central nervous system (CNS), and virus-induced hyperinflammatory and hypercoagulable states are commonly involved. Guillain-Barré syndrome (GBS) and its variants, dysfunction of taste and smell, and muscle injury are numerous examples of COVID-19 PNS (peripheral nervous system) disease. Likewise, hemorrhagic and ischemic stroke, encephalitis, meningitis, encephalopathy acute disseminated encephalomyelitis, endothelialitis, and venous sinus thrombosis are some instances of COVID-19 CNS disease. Due to multifactorial and complicated pathogenic mechanisms, COVID-19 poses a large-scale threat to the whole nervous system. A complete understanding of SARS-CoV-2 neurological impairments is still lacking, but our knowledge base is rapidly expanding. Therefore, we anticipate that this comprehensive review will provide valuable insights and facilitate the work of neuroscientists in unfolding different neurological dimensions of COVID-19 and other CoV associated abnormalities.
\end{abstract}

Keywords Nervous system · Coronavirus (CoV) - SARS-CoV-2 · COVID-19 · Neuropathogenesis · ACE2 · Multiple sclerosis $\cdot$ Cerebrovascular disease $\cdot$ Guillain-Barré syndrome (GBS)

\section{Introduction}

Since December 2019, the health effects of a novel coronavirus $(\mathrm{CoV})$ disease have been witnessed in a worldwide outbreak of severe pneumonia caused by a deadly infectious virus originating in Wuhan, China. From the first human CoV-positive cases detected in Wuhan (WHO 2020), coronavirus disease 2019 (COVID-19) has spread

Niraj Kumar Jha

nirajkumarjha2011@gmail.com; niraj.jha@sharda.ac.in

Extended author information available on the last page of the article rapidly in humans around the globe. SARS-CoV-2, a strain of $\mathrm{CoV}$, causes the clinical syndrome COVID-19, whose pulmonary manifestations have been well recorded. The increasing number of positive cases has reached more than 54.7 million, with 1,323,230 deaths reported as of November 15, 2020 (Worldometer 2020). A very interesting fact about this virus is that a higher lethality of infection has been recognized in those over the age of 65 and patients with comorbidities (Baud et al. 2020; Guan et al. 2020; Huang et al. 2020; Wang et al. 2020a, b, c, d).

There is increasing evidence of neurological complications detected in patients due to SARS-CoV-2, and this raises the question of whether SARS-CoV-2 is neurotropic and whether 
it contributes to post-infectious neurological complications. Two similar human CoVs, severe acute respiratory syndrome (SARS-CoV-1) and Middle East respiratory syndrome (MERS-CoV), have also been reported to be associated with neurological disease in uncommon cases. A handful of case reports have described neurological complications in patients with COVID-19 (Huang et al. 2020; Netland et al. 2008; Zhang 2020; Kim et al. 2017). However, owing to a lack of understanding of the specific mechanisms, it remains unclear to what extent SARS-CoV-2 itself affects or damages the nervous system, and what neurological symptoms are attributable to secondary mechanisms. Viral neuroinvasion may be achieved by several routes, including entry via the olfactory nerve, transsynaptic transfer across infected neurons, leukocyte migration across the blood-brain barrier (BBB), or infection of the vascular endothelium. SARS-CoV-2 mainly affects the lower respiratory tract, and the most common and frequent neurological complaints in COVID-19 are anosmia, ageusia, and headache, along with others including fever, fatigue, myalgia, dry cough, and diarrhea (Gutiérrez-Ortiz et al. 2020). Additionally, coma, seizure, stroke, encephalopathy, and impaired consciousness have also been observed (Gutiérrez-Ortiz et al. 2020). The identification and understanding of the array of COVID19-associated neurological diseases may lead to improved clinical outcomes and better treatment algorithms. This comprehensive review serves to recapitulate available data related to $\mathrm{CoV}$ in the nervous system, identify the potential tissue targets and entry routes of SARS-CoV-2 into the CNS, and address the array of clinical neurological manifestations and complications that have been recorded so far in COVID-19 and their potential pathomechanisms. Further neuropathological studies will be significant in order to understand the disease pathogenesis and the interconnection between SARS-CoV-2 and the CNS. Most importantly, longitudinal neurological and cognitive assessment of individuals after recovery from COVID-19 will be crucial for understanding the natural history of COVID-19 in the CNS and monitoring for any long-term neurological sequelae.

\section{Neurological Complications of SARS-CoV-2 and Other Coronaviruses}

Recent evidence suggests that the nervous system might also be involved in the COVID-19 pathophysiology. As revealed by a retrospective study of 200 patients in China, neurological symptoms were experienced by a subset of patients affected by COVID-19 (Mao et al. 2020). The neurological symptoms that were experienced include impaired consciousness, skeletal muscle symptoms, and acute cerebrovascular disease, all of which indicated the involvement of the peripheral nervous system (PNS) and central nervous system (CNS). Patients suffering from severe COVID-19 were more likely to exhibit these symptoms. Hyposmia and hypogeusia were other possible PNS symptoms that were observed. As patients were hospitalized at the time of publication, it was not possible to investigate the link between patient outcome and neurological symptoms. In another study conducted on the same group of patients, it was revealed that COVID-19 infection in 13 patients was followed by acute cerebrovascular diseases, including cerebral hemorrhage, ischemic stroke, and cerebral venous sinus thrombosis ( $\mathrm{Li}$ et al. 2020a, b).These features were observed more commonly in older patients and patients with severe disease. A second study conducted in France reported similar neurological manifestations as were revealed in a Chinese study, where 58 patients with COVID-19 experienced acute respiratory distress syndrome and had to be admitted to a hospital (Helms et al. 2020). Neurological symptoms were observed in $85 \%$ of the patients at various points in time, with consequences ranging from the discontinuation of neuromuscular blockade to admission to the intensive care unit (ICU). Neurological features included corticospinal tract dysfunction, encephalopathy, delirium, and agitation. Bilateral frontotemporal hypoperfusion and leptomeningeal enhancement were also revealed in a small subset of patients on conducting perfusion brain imaging and magnetic resonance imaging (MRI). Evidence of small acute ischemic stroke was also present in two patients. While further studies are needed to characterize the associated neurological manifestations, the number of COVID-19 cases with a reported acute neurological disorder is increasing, ranging from acute myelitis and Guillain-Barré syndrome (GBS) to hemorrhagic necrotizing encephalopathy (Karimi et al. 2020; Zhao et al. 2020a, 2020b; Poyiadji 2020; Moriguchi 2020; Sedaghat and Karimi 2020; Toscano et al. 2020). Compared to past instances of coronavirus epidemics, significantly fewer neurological associations have been established, but several case reports of patients with severe acute respiratory syndrome coronavirus (SARS-CoV) have described patients developing rhabdomyolysis, myopathy, and seizures (Lau et al. 2004; Tsai et al. 2005; Hung et al. 2003; Chao et al. 2003; Xu et al. 2005). In a study that involved 206 SARS patients, acute cerebrovascular disease was reported in five cases (Umapathi 2004). However, it is debatable whether this indicates a direct comparison between SARS pathophysiology and COVID-19. Acknowledging that in some cases these are associated with different diagnoses, and noting that they are rare presentations, the presence of RNA in both autopsied brain tissue (Xu et al. 2005) and cerebrospinal fluid (CSF) (Lau et al. 2004; Tsai et al. 2005; Hung et al. 2003) suggests a neurotropic component of the SARS coronavirus. Furthermore, several case reports of patients during the MERS-CoV outbreak noted neurological disorders, including delirium, neuropathy, and 
acute cerebrovascular disease (Kim et al. 2017; Algahtani et al. 2016; Arabi et al. 2015). Seizures in six participants and confusion in 18 patients were reported during another study that involved 70 MERS patients (Saad et al. 2014), although caution is warranted in the interpretation of such findings. There is little evidence that indicates the presence of MERS coronavirus in CSF as compared to SARS. It seems to be the same case with COVID-19; where evidence of the presence of the virus in the CSF is restricted to a single report (Moriguchi 2020) whose findings have not been replicated by other studies (Helms et al. 2020; Karimi et al. 2020; Toscano et al. 2020). Over a million confirmed cases of COVID-19 have been reported worldwide, and while definitive evidence is sparse, emerging publications and preprints justify careful consideration of the neurological associations with COVID19 infection (Fig.1).

\section{Direct Neuroinvasive Effects of SARS-CoV-2 and Other Coronaviruses on the Nervous System}

An important line of research pertains to the question of whether severe acute respiratory syndrome coronavirus 2 (SARS-CoV-2) is neuroinvasive. Much published evidence is available on this issue. Similar to SARS-CoV, the molecular mechanisms underlying cell invasion by SARSCoV-2 are related to the capacity of the virus to bind to angiotensin-converting enzyme 2 (ACE2) receptors. The
CNS is a potential target for SARS-CoV-2, because the ACE2 receptors are highly expressed in the neurons and glial cells in the CNS and epithelial cells of the digestive and respiratory systems (Xu et al. 2020a; Zhang et al. 2020; Lukassen et al. 2020; Wong et al. 2020; Baig et al. 2020). Emerging data suggest that ACE2 receptors are expressed in multiple regions of the human and mouse brain, including the posterior cingulate cortex, motor cortex, substantia nigra, ventricles, olfactory bulb, middle temporal gyrus, nucleus of tractus solitarius, ventrolateral medulla, and dorsal motor nucleus of the vagus nerve, and on several key cell types that make up the CNS including neurons, astrocytes, microglia, and oligodendrocytes (Fig. 2) (Chen et al. 2020a; Xia and Lazartigues 2008; Doobay et al. 2007). Moreover, neuronal death in mice has been exhibited with SARS-CoV as it invades the CNS through the cribriform plate of the ethmoid bone and, subsequently, the olfactory neuroepithelium (Netland et al. 2008). The entry of SARS-CoV-2 into the CNS is also possible through the hematogenous route. With the presence of the virus in the general circulation and the slow blood flow, the ACE2 receptors expressed in the capillary endothelium may interact with SARS-CoV-2 (Zhang et al. 2020). Endothelial damage and cerebral bleeding observed in patients suffering from COVID-19 may also be due to this mechanism. Moreover, preliminary evidence suggests that there might be prognostic implications in the acute phase for the neuroinvasive potential of SARSCoV-2. It has been hypothesized that any death that is
Fig. 1 Schematic representation showing the possible mechanisms underlying neurological consequences of COVID-19. CBF, cerebral blood flow; CPP, cerebral perfusion pressure

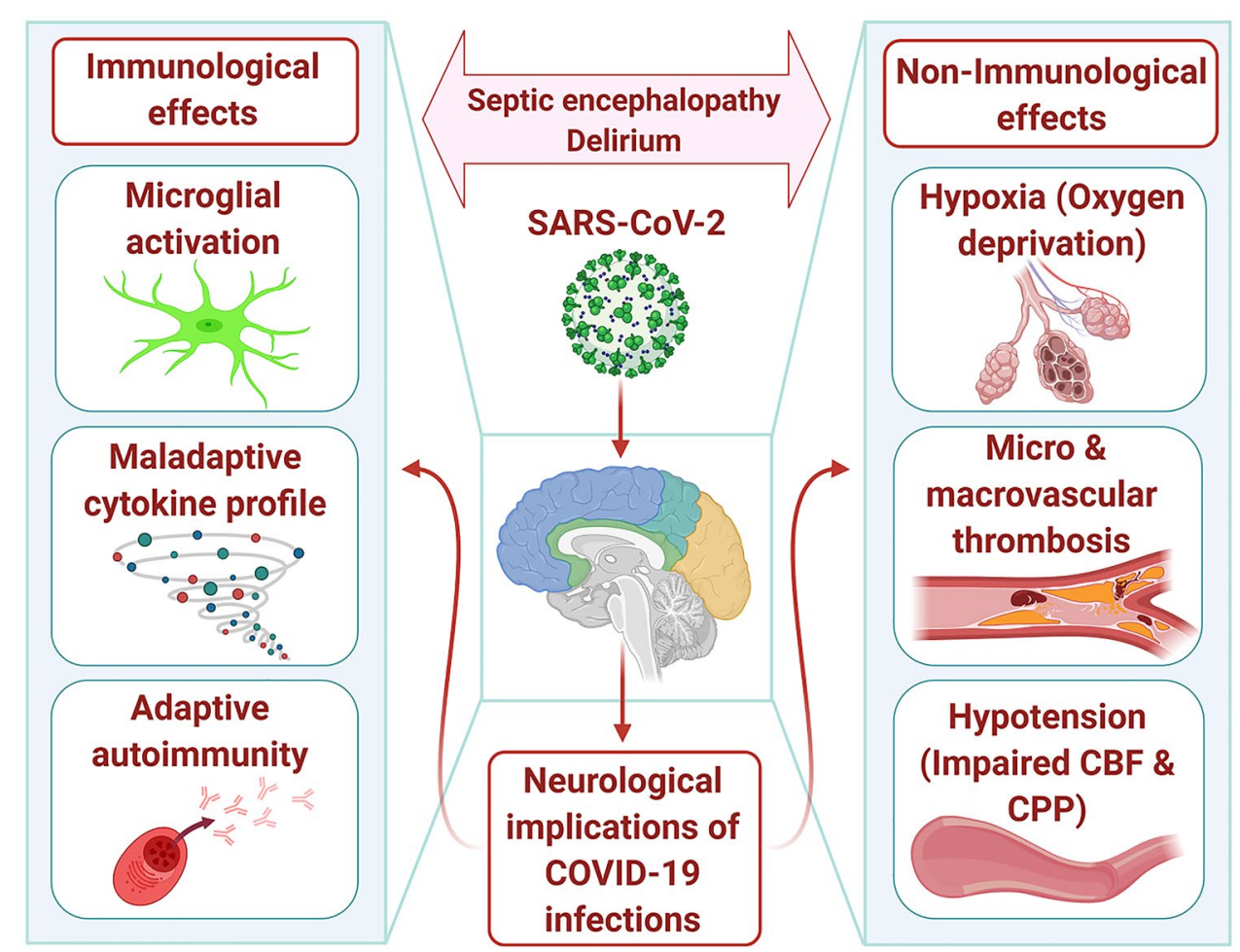


Fig. 2 a Human cells that express ACE2 receptors in the CNS. b Brain areas that express ACE2 receptors. c Binding of SARS-CoV-2 to a neuron (ACE2 receptors on a medullary neuron binding to the SPIKE protein on SARS-CoV-2)

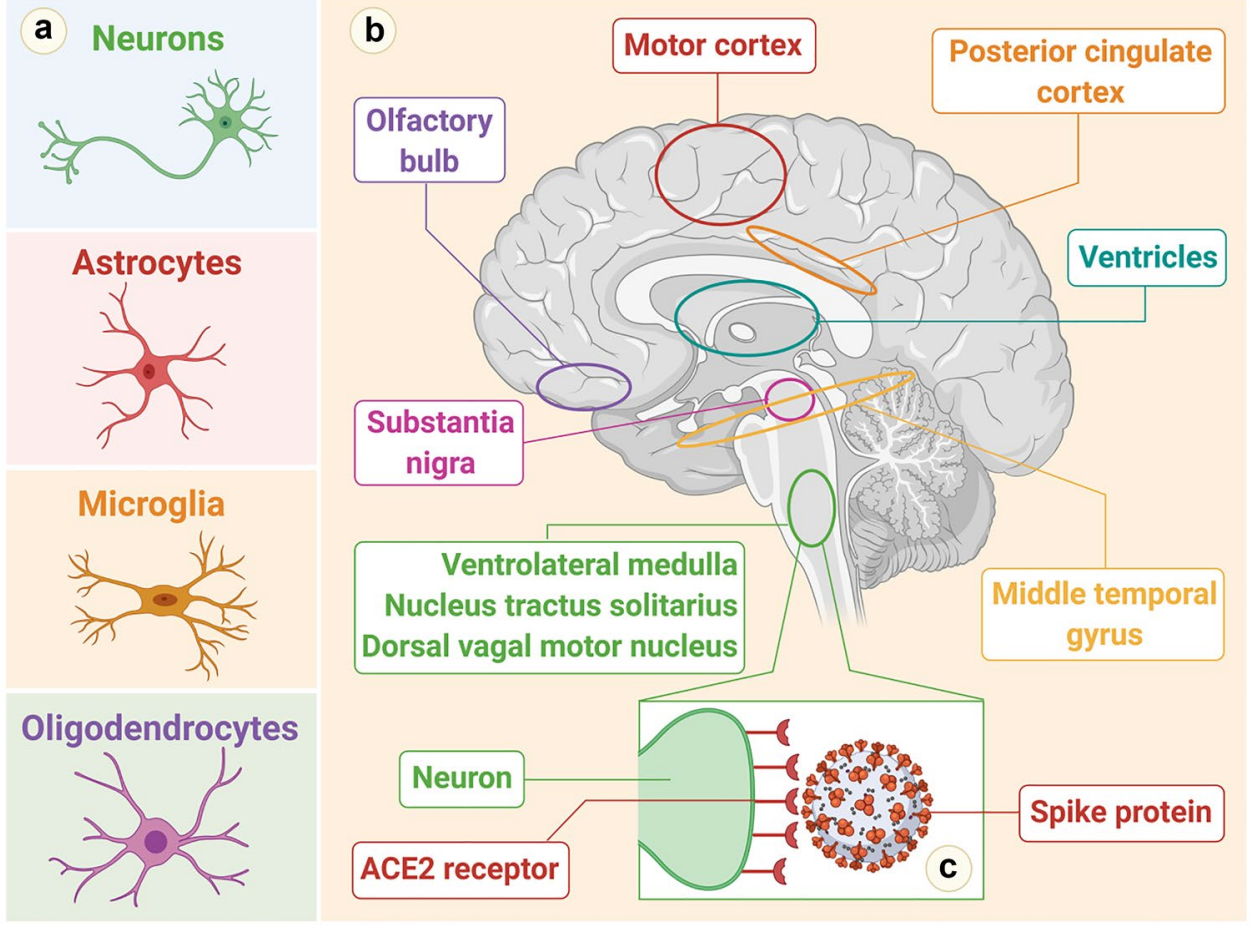

entirely due to severe respiratory involvement is mediated by central hypoventilation syndrome secondary to CNS invasion ( $\mathrm{Li}$ et al. 2020a, b). When a review of the Wuhan reports involving 214 COVID-19 patients was conducted, neurological symptoms were observed in more than $36 \%$ of individuals. Patients who exhibited neurological manifestations suffered from severe COVID-19. In addition, the neurological symptoms that were reported most frequently were acute stroke (both ischemic and hemorrhagic), skeletal muscle damage, and impaired consciousness (Mao et al. 2020). Evidence of CNS invasion has subsequently been displayed in patients affected by SARS-CoV-2. Researchers at the Beijing Ditan Hospital used genome sequencing to identify SARS-CoV-2 in the CSF of a patient affected with clinical encephalitis and COVID-19, but it has still not been determined whether SARS-CoV-2 remains in the CNS over the medium or long term (Mao et al. 2020). However, viral latency in the CNS has been described for other viruses as well, including some coronaviruses. For example, in the CNS, human coronavirus OC43 (HCoV-OC43) was detected after more an year postinoculation in a murine model of coronavirus encephalitis (Xiang et al. 2019; Jacomy et al. 2006). How the virus can persist in the CNS is a question that has been the subject of debate. There have been suggestions that inflammatory and cytolytic strategies that have shown potential in the control of viral infection cannot be used in the brain by the immune system, as they can have potentially devastating consequences. Thus, another type of immune response is initiated in the CNS, which favors viral latency in the CNS as well as reactivation in situations that are entirely favorable (Miller et al. 2016). The possibility that SARS-COV-2 might remain suppressed in the CNS cannot be ruled out entirely. If it does, delayed onset of neurological symptoms might be observed as a result of viral reactivation in the medium or long term. This might eventually result in the reactivation of a series of processes that are neuroinflammatory in nature and are linked to neurodegenerative diseases.

\section{Indirect Neuroinvasie Effects of Coronaviruses on the Nervous System}

There may be an indirect effect of SARS-CoV-2 on the $\mathrm{CNS}$, more specifically on the progression of disorders that are neurodegenerative in nature. In the past few years there have been descriptions of a strong correlation between neuroinflammation, microbiota, and CNS diseases. SARSCoV-2 is also known to trigger inflammation and intestinal dysbiosis, infecting the mucosa cells, which potentially results in short-term and long-term alterations in the gut microbiota. This usually leads to the development of neurodegenerative diseases and neurodegeneration (Lin et al. 2018). 


\section{Possible Mechanisms of Coronavirus Infections in Neuronal Impairment}

\section{Direct Infection Injury}

There have been suggestions that direct invasion of the nervous system by viruses is possible, which often lead to nerve damage. This is based on the detection of proteins and genetic materials of different viruses in tissue samples of the nervous system, including the CSF/brain (Koyuncu et al. 2013; Leber et al. 2016).

\section{a) Blood Circulation Cascades}

Japanese encephalitis virus (JEV) is a classic virus that uses the circulation of the blood to enter the CNS. It then undergoes multiplication in the vascular cells of the skin area, impacted by the mosquito bite. Subsequently, for reproduction in the mononuclear macrophages throughout the body, the virus is released into the blood. Through the cytokines produced, the secondary release into the bloodstream increases the BBB permeability. This promotes the virus's entry into the brain, thereby leading to viral encephalitis (Unni et al. 2011). Additional studies are expected to determine whether the $\mathrm{CoV}$, particularly SARS$\mathrm{CoV}-2$, can use the blood circulation pathway to invade the nervous system, as present evidence is extremely rare (Koyuncu et al. 2013; Desforges et al. 2019).

\section{b) Neuronal Cascades}

The neuronal pathway is an important vehicle facilitating the entry of neurotropic viruses into the CNS. Migration of the viruses is possible through infection of motor or sensory nerve endings, achieving retrograde or anterograde neuronal transport through the motor proteins, dynein, and kinesins (Swanson and McGavern 2015). Olfactory neuron transport is an example of a neuronal pathway. The olfactory bulb in the forebrain and the nasal cavity and olfactory nerves have a distinct anatomical structure, which makes it an efficient channel between the CNS and nasal epithelium (Koyuncu et al. 2013). Consequently, during the initial stages of infection or nasal vaccination, $\mathrm{CoV}$ can use the olfactory tract to enter the brain (Desforges et al. 2019; Mori 2015). For instance, once $\mathrm{CoV}$ infects the nasal cells, it can use the olfactory bulb and olfactory nerves to reach the CSF and the entire brain within one week, leading to demyelinating reaction and inflammation. However, the invasion of $\mathrm{CoV}$ into the CNS was restricted after removal of the olfactory bulb in mice (Bohmwald et al. 2018). SARS virus particles as well as genome sequences in brain neurons were also detected by $\mathrm{Gu}$ et al. (Gu et al. 2005). This observation suggests that $\mathrm{CNS}$ can be invaded by $\mathrm{CoV}$ through the periphery via neural pathways.

\section{Hypoxia Brain Injury}

Formation of transparent membranes, edema, and diffusion of alveolar and interstitial inflammatory exudation is caused by a virus when it proliferates in the lung tissue cells. This results in increased anaerobic metabolism in the mitochondria of brain cells and causes hypoxia through alveolar gas exchange disorders in the CNS (Abdennour et al. 2012). Various disorders can be caused by the accumulation of the acid, including obstruction of cerebral blood flow, cerebral vasodilation, interstitial edema, swelling of brain cells, and even headache due to ischemia and congestion (Abdennour et al. 2012). Cerebral circulation disorder and cerebral edema can also quickly worsen if the hypoxia continues unabated. Brain function gradually deteriorates with intracranial hypertension and may lead to bulbar conjunctival edema, drowsiness, and coma, (Abdennour et al. 2012). Moreover, acute cerebrovascular diseases such as acute ischemic stroke may be induced by hypoxia in patients who are at a higher risk of developing cerebrovascular disease. Hypoxia injury may lead to further damage to the nervous system, because severe hypoxia is commonly found in patients affected by COVID-19 (Guo et al. 2020).

\section{Immune-Based Injury}

The immune system might mediate the viral infection that causes damage to the nervous system (Klein et al. 2017). The development of a systemic inflammatory response syndrome (SIRS) is closely related to the pathology of severe viral infections. In cases of pneumonia triggered by $\mathrm{CoV}$ infection, abnormal initiation of SIRS is possible. The risk of injury to the nervous system and immune damage can be prevented by timely anti-inflammatory intervention (Mehta et al. 2020; $\mathrm{Fu}$ et al. 2020). In addition, a significantly higher number of casualties have been caused by COVID-19 and SARS predominantly due to multi-organ failure (MOF), which is a result of virus-induced SIRS or SIRS-like immune disorders (Yin et al. 2004; Chen et al. 2020b). The ability of CoV infections to persist and infect microglia, macrophages, and astrocytes in the CNS is crucial. A pro-inflammatory state can also be induced by glial cell activation via a neurotropic virus (Li et al. 2004). There is a positive correlation between interleukin (IL-6), which is an important member of the cytokine storm, and the symptoms of COVID-19 (Wan et al. 2020). Experiments have confirmed that a large number of inflammatory factors, including IL-12, IL-15, IL-6, and tumor necrosis factor alpha (TNF- $\alpha)$, are secreted by primary glial cells once they have been infected with $\mathrm{CoV}$ (Bohmwald 
et al. 2018). Chronic inflammation and brain damage are also caused by the activation of immune cells in the brain.

\section{Angiotensin-Converting Enzyme 2 (ACE2)}

As a cardio-cerebral vascular protection factor, ACE2 exists in various organs, including the skeletal muscles and the nervous system. It plays an essential role in anti-atherosclerosis mechanisms and regulation of blood pressure (Miller and Arnold 2019). Moreover, ACE2 is an extremely important target for various influenza viruses and $\mathrm{CoV}$ (Turner et al. 2004; Wrapp et al. 2020; Yang et al. 2014). The increased risk of cerebral hemorrhage and abnormally elevated blood pressure may be caused by these viruses by binding to the ACE2 receptors. Moreover, the virus has the potential to damage the BBB and enter the CNS by attacking the vascular system, as the ACE2 expressed in the capillary endothelium can interact with the SARS-CoV-2 spike protein (Baig et al. 2020).

\section{Other Associated Factors}

Neurological damage can be caused by $\mathrm{CoV}$ infections, as the biological properties of the CNS may facilitate their exacerbation. The invasion of the virus is inhibited by the lack of permeability of the blood vessels due to the dense parenchymal structure of the CNS. However, if any virus has access to the CNS, it is not easily removed (Reinhold and Rittner 2017). The eradication of viruses in nerve cells depends mainly on the role of cytotoxic $\mathrm{T}$ cells because of the lack of major histocompatibility complex (MHC) antigens in nerve cells, although a relatively protective effect is provided by apoptosis of mature neurons after virus infection (Wuthrich et al. 2015). Moreover, the continued existence of the virus also contributes to the homeostasis characteristics of the cells in the CNS (Reinhold and Rittner 2017). The possible mechanisms of nervous system injury caused by $\mathrm{CoV}$ are depicted in (Fig.3).

\section{Pathobiology of SARS-COV-2 Neuroinvasion}

At present, it is unclear how the human CNS is invaded by SARS-CoV-2. Few researchers have postulated plausible mechanisms of neuroinvasion of SARS-CoV-2 through transsynaptic or BBB spread (Fig. 4) (Dube et al. 2018).

\section{Transsynaptic Viral Spread}

In the literature, the path of transsynaptic spread has been described for $\mathrm{HCoV}-\mathrm{OC} 43$, hemagglutinating encephalomyelitis virus-67 (HEV67), and avian bronchitis virus (Dube et al. 2018). For inter- and intra-neuronal spread of neurotrophic virus, axonal microtubules facilitate molecular movement across axons either in antegrade or retrograde fashion (Desforges et al. 2019; Berth et al. 2009). A few reports
Fig. 3 Schematic representation showing pathomechanisms of nervous system injury caused by coronaviruses (CoV). ACE2, angiotensin-converting enzyme 2; BBB, blood-brain barrier; IL, interleukin; MHC, major histocompatibility complexes; SIRS, systemic inflammatory response syndrome

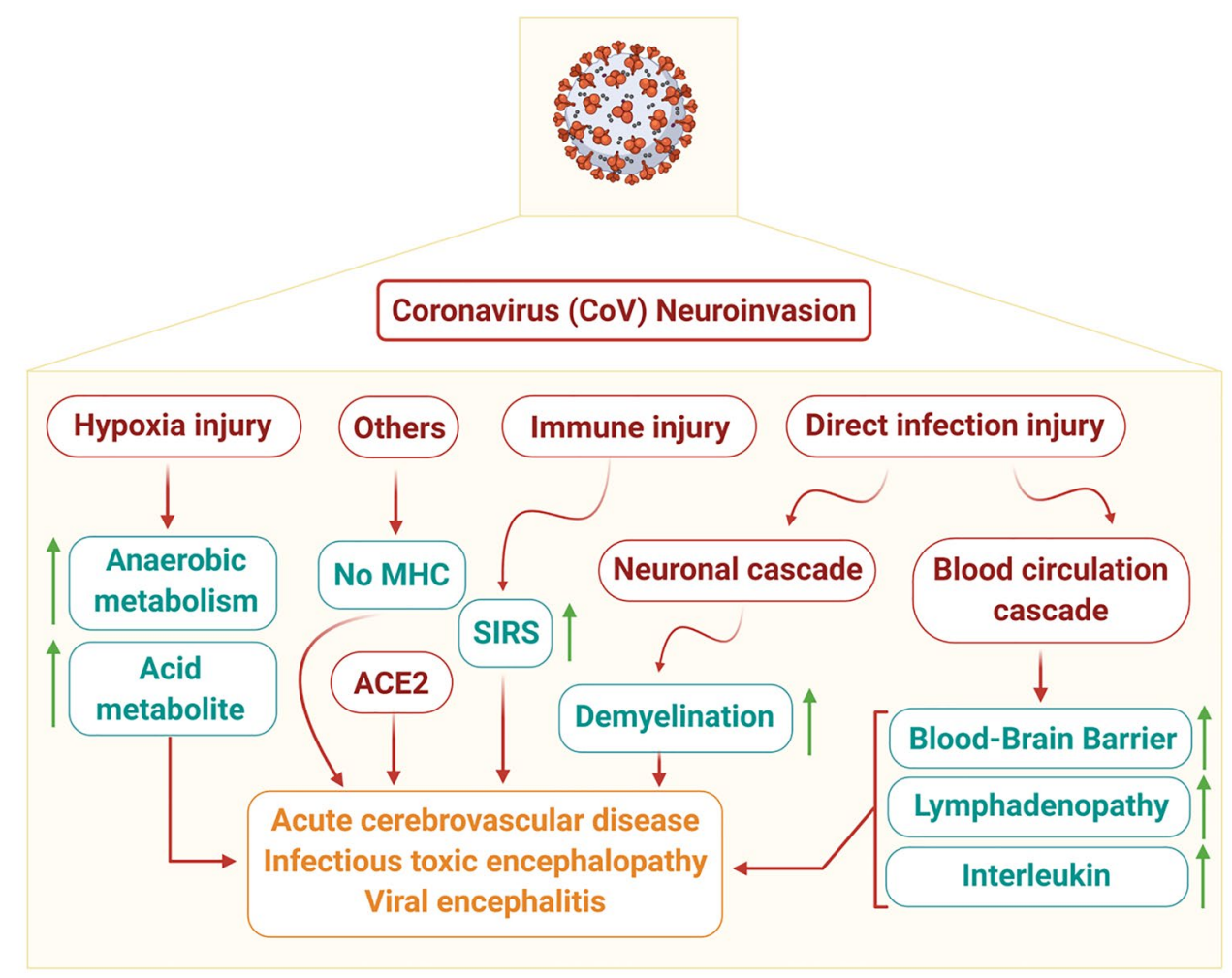




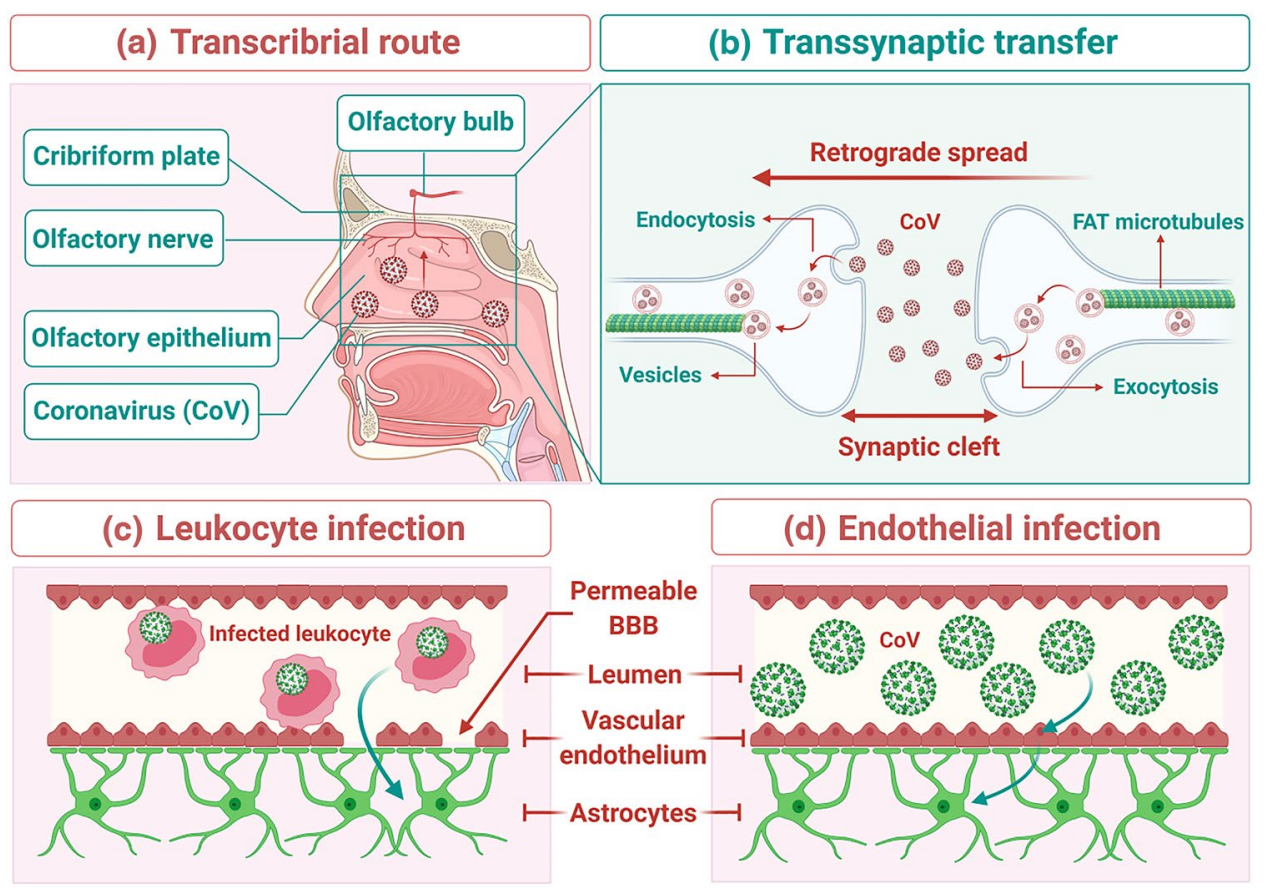

Fig. 4 Transsynaptic viral spread: (a) Spread via the transcribrial route: Coronavirus $(\mathrm{CoV})$ has been shown to spread via the transcribrial route from the olfactory epithelium along the olfactory nerve to the olfactory bulb within the CNS. (b) Spread via transsynaptic transfer: CoV has been shown to spread retrograde via transsynaptic transfer using an endocytosis or exocytosis mechanism and a fast axonal transport (FAT)

have noted an isolated loss of smell (anosmia) and loss of taste (ageusia) with or without the invasion of respiratory system (Giacomelli et al. 2020). Researchers noted that the direct entry of SARS-CoV-2 along the olfactory nerve is a potential route for the virus to gain entry into the CNS (Matsuda et al. 2004). Few reports have proved a transcribrial route of spread in preclinical studies for SARS-CoV-1, MERS-CoV, and HCoVOCR43 models through the intranasal route (McCray et al. 2007). Brann et al. and Fodulian et al. suggested the presence of ACE-2 receptors in sustentacular stem cells in the olfactory epithelium (Fodoulian et al. 2020; Brann et al. 2020). However, there is a scarcity of reports of olfactory neuropathy that is SARS-related (Hwang 2006). The most important COVID-19 infection features, which are being increasingly recognized as hyposmia and anosmia, are now the more common presenting symptoms (Mao et al. 2020; Lechien et al. 2020; Menni et al. 2020; Wolfel et al. 2020; Giacomelli et al. 2020; Bagheri et al. 2020). According to animal studies, it has been suggested that SARS-CoV can reach the brain and promote neurodegeneration through the olfactory route (Netland et al. 2008). These clinical reports help researchers trace the path of olfactory epithelial damage underlying clinical anosmia (Brann et al. 2020; Fodoulian et al. 2020). mechanism of vesicle transport to move virus along microtubules back to neuronal cell bodies. Mechanisms of spread across the BBB: (c) Leukocyte infection: Infected leukocytes can cross the BBB to infect the CNS through the Trojan horse mechanism. (d) Endothelial infection: Infected vascular endothelial cells have been shown to spread SARS-CoV-2 to glial cells in the CNS

\section{Blood-Brain Barrier (BBB) Spread}

Hematogenous dissemination is one of the suggested mechanisms, wherein the endothelial cells or leukocytes are infected by the virus that traverses from the bloodstream into the CNS (Desforges et al. 2019). The neural spread of SARS-CoV-2 via the BBB is through the spread of infection across vascular endothelial cells due to the presence of ACE2 receptors in the endothelial cells (Paniz-Mondolfi et al. 2020). Once a neurotrophic virus gains entry along vascular endothelial cells, the virus is integrated with cells containing ACE2 receptors (neurons, glia and vascular channels) and is able to exert its effects (Baig et al. 2020). Another possible pathway that has been suggested is the passage of infected leucocytes through the BBB (Desforges et al. 2014). This mechanism of neurotropism has been demonstrated in the case of the human immunodeficiency virus (HIV) and SARS-CoV1(Kim et al. 2003; Spiegel et al. 2006; Nicholls et al. 2006; Trojanowicz et al. 2017). In SARS-CoV-2 infection, T cells facilitate viral infection but not replication (Wang et al. 2020a). Due to the widespread systemic effects of COVID19 , BBB permeability is increased, and hence CNS entry 
is gained through the passage of infected immune cells (Sankowski et al. 2015). These studies aiming to improve an understanding of SARS-CoV-2 neurotropism provide promising avenues for future research.

\section{Coronavirus and Neurological Disorders}

\section{Multiple Sclerosis}

The human coronavirus (HCV) has been used in several experimental models for the identification of the environmental component that triggers changes in the autoimmune system in multiple sclerosis (MS) cases (Sun 1995; Houtman et al. 1995; Wege 1995; Arbour 1999). An important role in MS pathophysiology is played by the tolllike receptors (TLRs) that are involved in the recognition of pathogens and host defense. Some researchers have postulated that these receptors recognize the viral particles and contribute to the modification of the immune response of patients developing MS. This interaction also suggests a probable link between viral infections (including CoV) and the development of demyelinating disease (Duffy and O'Reilly 2016). A large panel comprising samples of human brain autopsy was subjected to an observational study. This was done for targeted detection of HCV RNA. In addition, reverse transcription polymerase chain reaction (PCR) for OC43 and 229E CoV strains was performed on the samples collected from 39 patients affected by MS and 51 patients suffering from several varying neurological conditions or normal controls. A significantly higher prevalence of OC43 was reported in the results for individuals with MS as compared to the controls [35.9\% (14 of 39) vs $13.7 \%$ (7 of 51)] (Arbour 2000). Another observational study showed that 4 out of 21 specimens from a white matter plaque, normal-appearing white matter, gray matter, and cervical cord tissue of MS patients tested for HCV-229E nucleic acid consistently gave positive results, while none of the 11 control brain specimens did so. A similar study reported the detection of murine-like $\mathrm{CoV}$ in 12 of $22 \mathrm{MS}$ brains. Another study also reported that murine-like $\mathrm{CoV}$ was detected in 12 out of 22 MS brain specimens (Murray 1992). In addition to the isolation of HCV from the brains of patients suffering from MS, this association is supported by the observation of particles that appeared to be similar to the $\mathrm{CoV}$ in perivascular cuffing of an MS plaque intrathecal synthesis of antibodies to HCV-OC43 and HCV-229E in a significant number of patients suffering from MS (Stewart et al. 1992). Persistence of the infection in a leukocyte cell line and direct inoculation of the endothelial cells that act as a BBB enables $\mathrm{CoV}$ to infect dendritic cells and macrophages. It also enables $\mathrm{CoV}$ to effect changes in the whole innate immune system (Gerna 2007). In a separate study, experimental modeling was performed on susceptible strains of mice that were inoculated with the CoV JHMV strain. The results showed the development of an acute encephalomyelitis followed by a chronic demyelinating disease (Libbey et al. 2014). Multiple models of murine $\mathrm{CoV}$ have been used to induce demyelinating diseases in rodents (Houtman et al. 1995), either through a consistent infection of astrocytes and oligodendrocytes or through autoimmune simulation against the myelin basic protein. The reason for this is the contribution to the postulated molecular mimicry depicted by it (Boucher 2007). However, irrespective of all these findings that have expressed some association between the alpha and beta $\mathrm{CoV}$ along with the demyelinating disease, no connection can be demonstrated between MS and SARS$\mathrm{CoV}-2$, though a subsequent association cannot be ruled out.

\section{Acute Disseminated Encephalomyelitis}

Several experimental studies that inoculated $\mathrm{CoV}$ in mice showed a loss of myelin in the mouse spinal cords during the acute phase of the acute disseminated encephalomyelitis (ADEM) (Wu and Perlman 1999), and subsequent destruction of myelin after around 2-3 weeks of infection (Savarin 2008; Fehr and Perlman 2015). There was another case where a 15-yearold patient exhibited signs of initial upper respiratory symptoms along with subsequent ADEM. In this case, the nasopharyngeal specimens and the CSF showed positive results for HCV-OC43 (Yeh 2004). Another report pertaining to the case of a 71-yearold patient who tested positive for MERS-CoV noted that on the 24th day of the disease, new lesions were discovered in the patient's bilateral pons, corpus callosum, periventricular deep white matter, upper cervical cord, left cerebellum, and midbrain (Algahtani et al. 2016). Further clinical research is needed to support the relationship between $\mathrm{CoV}$ and $\mathrm{ADEM}$, even though the evidence indicates the persistence of the CoV RNA in the nervous system after the infection's acute phase has occurred and has already caused neuronal loss.

\section{Viral Encephalitis}

Encephalitis leads to inflammatory lesions in the brain parenchyma that are caused by pathogens and include nerve tissue lesions and neuronal damage. This condition is characterized by its acute onset, and common symptoms include vomiting, high fever, convulsions, headache, and consciousness disorders (Ellul and Solomon 2018). Early diagnosis of the condition is critical for patient survival. A treatment team from the Beijing Ditan Hospital reported that during the ongoing pneumonia epidemic, the presence of SARS-CoV-2 was confirmed in the CSF of COVID-19 patients through genome sequencing. This presented clinical verification of the presence of viral encephalitis (Xiang et al. 2020) and offered clear indications for encephalitis caused by $\mathrm{CoV}$. 


\section{Infectious Toxic Encephalitis}

Infectious toxic encephalitis, also known as acute toxic encephalopathy, is related to a specific type of reversible brain dysfunction syndrome, which is a result of several factors including metabolism disorders, toxemia, and hypoxia experienced during the process of acute infection (Mizuguchi et al. 2007; Tauber et al. 2017; Young 2013). Cerebral edema is one of the basic pathological changes witnessed during this condition, although CSF analysis indicates no evidence of inflammation. The clinical symptoms of the condition are diverse and complex. Patients suffering from a mild course of the disease can develop mental disorders, headache, delirium, and dysphoria, whereas patients who are seriously affected can experience loss of consciousness, disorientation, paralysis, and coma (Dobbs 2011; Mizuguchi et al. 2007). Another significant cause of this condition is an acute viral infection, which has been exemplified by a respiratory infection caused by CoV. Severe viremia and hypoxia are often observed in patients suffering from COVID-19 (Guo et al. 2020), as they have the potential to lead to toxic encephalopathy. Additionally, almost $40 \%$ of patients with COVID-19 develop symptoms such as disturbed consciousness, headache, and other symptoms of brain dysfunction (Mao et al. 2020). Another autopsy study revealed that edema was detected in the brain tissues of COVID-19 patients (Xu et al. 2020b). Although detailed studies are urgently needed, these findings collectively indicate that infectious toxic encephalopathy can be caused by COVID- 19 .

\section{Acute Encephalitis}

In one study, HCV-OC43 testing was used to investigate the notion that an infectious respiratory pathogen could infiltrate the CNS, ultimately leading to swelling and neuroinflammation. The study reported that the infection caused neuronal degeneration, which eventually led to neuronal apoptosis. After the inoculation of HCV-OC43 in susceptible mice samples, the mice developed acute encephalitis, with viral RNA present for several months in surviving animals leading to neural degeneration (Jacomy et al. 2006). Full-length HCV-OC43 RNA was recovered from the brain of an 11-month-old boy who exhibited symptoms of viral encephalitis and severe combined immunodeficiency after cord blood transplantation. The patient was unable to survive and died 1.5 months after transplantation. Two months after the onset of symptoms, RNA sequencing of a brain biopsy sample was obtained, and it exhibited the presence of HCV-OC43. This diagnosis was further confirmed by brain immunohistochemical analysis and real-time PCR (Morfopoulou 2016). After a 3-day history of fever, cough, and altered psychological status, necrotizing hemorrhagic encephalitis was found in a middle-aged woman affected by
COVID-19. Non-contrast computed tomography (CT) images of the head showcased symmetric hypoattenuation within the bilateral medial thalami. Magnetic resonance imaging (MRI) further demonstrated hemorrhagic lesions within the medial temporal lobes, bilateral thalami, and sub-insular regions (Poyiadji 2020). In yet another case, after experiencing fever, headache, and fatigue, a 24-year-old man presented with altered mental status and seizures, which further led to impaired consciousness. Laboratory and clinical evidence indicated viral meningoencephalitis, and detection of SARSCoV-2 was determined in the RT-PCR analysis of the CSF. A brain MRI was conducted and showed alterations in the right wall of the lateral ventricle, the right mesial temporal lobe, and the hippocampus, indicating SARS-CoV-2 meningitis. Surprisingly, the results for SARS-CoV-2 were negative in the RT-PCR of the nasopharyngeal swab specimen, raising the possibility of COVID-19 independent mechanisms of neuropathogenesis (Moriguchi 2020). Conclusive evidence for establishing the relationship between COVID-19 and encephalitis is still needed, despite the postulated mechanisms of clinical reports and neuronal colonization.

\section{Acute Cerebrovascular Disease}

Substantial available evidence points specifically to respiratoryrelated infection as an independent risk factor for acute cerebrovascular disease (Elkind 2007; Warren-Gash et al. 2018). Data derived from an experimental mouse model indicate that ischemic brain injury can be aggravated by the influenza virus, which triggers a cytokine cascade and significantly enhances the risk of cerebral hemorrhage post-treatment with a tissuetype plasminogen activator (Muhammad et al. 2011). It has been widely reported that SARS-CoV-2 can cause cytokine storm syndromes, which might be one factor indicating that acute cerebrobasilar disease can be caused by $\mathrm{CoV}$ (Mehta et al. 2020; Chen et al. 2020d). A severe reduction in the platelet count and an increase in D-dimer levels are exhibited by critically ill patients severely affected by SARS-CoV-2. This can render patients vulnerable to different acute cerebrovascular events (Wang et al. 2020b). Hence, there is a significant likelihood that patients with a risk of developing cerebrovascular disease during $\mathrm{CoV}$ infections must be alert to the occurrence of acute cerebrovascular events.

\section{Cerebrovascular Disease}

One of the lesser-known complications of viral CNS infections is stroke. In Singapore, out of 206 SARS-CoV patients, five patients were reported to have large vessel stroke. Out of the four patients who were reported to be critically ill, three eventually died. In two patients, significant hypotension occurred just prior to the onset of stroke, along with disseminated intravascular coagulation and cardiac dysfunction 
(Umapathi 2004). An observational report pertaining to patients who were critically infected with SARS-CoV found an increased incidence of venous thromboembolism among patients (Lew 2003). A case series in Wuhan reported the occurrence of 14 strokes among a total of 214 patients affected by COVID-19. The data revealed that patients who exhibited cardiovascular risk factors and severe systemic presentation were extremely likely to be affected by acute cerebrovascular disease (Mao et al. 2020). In another retrospective study, stroke occurred in elderly patients who were affected with COVID19 and exhibited multiple cardiovascular risk factors. In all cases, the mechanism of vascular damage was documented as large vessel disease (Avula 2020). More recently, five cases of stroke were reported in the context of COVID-19. Various vascular risk factors including hypertension, diabetes, and dyslipidemia were present in three of the younger patients. In all of these cases, evidence of large vessel occlusion was documented, and these vessels were treated with endovascular therapy. However, this association between stroke and COVID19 is likely due to the similar risk factors shared by the two conditions. Adequate evidence is available that indicates the seriousness of COVID-19 infection in humans pertaining to the presence of different cardiovascular comorbidities such as diabetes and hypertension and large vessel disease in the elderly (Guo 2020). A recent meta-analysis comprising eight studies from China covering 46,248 infected patients indicated that the highly prevalent comorbidities were diabetes (8\%) and hypertension (17\%), followed by heart conditions (cardiovascular diseases) (5\%) (Yang 2020; Zhou 2020). In several cases where patients exhibited no substantial vascular risk factors, the highly significant cerebrovascular disease mechanism was the hypercoagulability induced by SARSCoV-2 (Avula 2020; Panigada 2020). When it comes to COVID-19 infection, there is an increased risk of stroke in those patients who have exhibited an earlier history of different vascular risk factors (Guo 2020; Yang 2020; Zhou 2020). Additionally, there is a chance that such patients will face severe complications such as hypotension, arrhythmogenic cardiomyopathy, shock heart failure, and disseminated intravascular coagulation. This could most certainly lead to large vessel occlusion, embolic mechanisms of stroke, and hypoperfusion (Wang et al. 2020c; Chen 2020d; Avula 2020; Zhou 2020; Oxley et al. 2020). In a detailed observational study that comprised 138 patients affected by COVID-19, 7.2\% of the patients showed indications of the presence of acute cardiac injury, $8.7 \%$ of infected patients exhibited shock, and $16.7 \%$ showed symptoms of arrhythmia (Wang et al. 2020d). Another observational study conducted on 191 patients in China showed that $20 \%$ of the patients had septic shock complication, $17 \%$ had acute cardiac injury, $23 \%$ had heart failure, and 19\% had coagulopathy (Zhou 2020). All these risk factors potentially predispose patients to stroke (Powers 2019). Further research is required to clarify the presence of specific viral factors that directly cause arteritis, hypercoagulability, and endothelial dysfunction that might eventually lead to brain bleeding or ischemic stroke (Powers 2019).

\section{Guillain-Barré Syndrome (GBS) and Peripheral Nerve Disorders}

Guillain-Barré syndrome (GBS) is an uncommon neurological condition in which the body's immune system mistakenly attacks part of the PNS (the network of nerves located outside of the brain and spinal cord). GBS is also known as acute inflammatory demyelinating polyneuropathy (AIDP), which can develop after a respiratory/gastrointestinal infection (Nguyen and Taylor 2020). It is supposed that a molecular mimicry mechanism of viruses, in which infecting viruses likely share epitopes similar to components of peripheral nerves (which activate autoreactive B or T cells), is accountable for its occurrence. The immune system produces antibodies, which are responsible to fight the virus cross-react and bind to components of the PNS, causing neuronal dysfunction. After SARS-CoV-1 infections both AIDP and acute motor axonal neuropathy (AMAN) variants have been reported (Tsai et al. 2005). Cases of Bickerstaff brainstem encephalitis, AMAN, and AIDP have been reported in the setting of MERS-CoV (Kim et al. 2017). However, reports of GBS in patients with COVID-19 are emerging. In Italy, a case series reported five cases of GBS after COVID-19 infection (Toscano et al. 2020). In four cases, patients developed lower-extremity weakness and presented paresthesias. Patients developed symptoms a mean of 5-10 days after onset of viral symptoms. Electromyography studies showed that three patients had AMAN and two had AIDP. Additional case reports describe a patient from Italy with Miller-Fisher-variant GBS and a patient in Iran with AMAN (Gutierrez-Ortiz et al. 2020; Sedaghat and Karimi 2020). A clinical case of acute transverse myelitis was also reported from Wuhan, but related CSF and MRI findings were not available. The patient presented flaccid lowerextremity paralysis with loss of pinprick sensation and paresthesias below the T10 level, and was effectively treated with intravenous immunoglobulin and steroids (Zhao et al. 2020a, b, c).

\section{Other Related Neurological Complications}

Loss of taste (dysgeusia/ageusia) and perturbation of smell (hyposmia/anosmia) have been reported as one of the striking manifestations of symptoms in patients with COVID-19. However, there are several uncertainties involved, including the specificity of the symptoms and the frequency of the symptoms as a probable diagnostic clue 
for COVID-19 in comparison to other symptomatically similar ailments like influenza, and the implications for the understanding of the pathogenesis of the virus. Impairment of smell was noticeable in 5\% of the 214 hospitalized patients, and a loss of taste was reported in $6 \%$ of the patients in the Wuhan COVID-19 series (Mao et al. 2020). As a result of incomplete evaluations in the hospitalized patients, it is probable that the frequency of these symptoms were underrepresented. A subsequent study was conducted on 31 patients, in which a loss of smell was reported in $81 \%$ of the COVID-19 patients (29\% hyposmia, $46 \%$ anosmia, and $6 \%$ dysosmia), while impaired sense of taste was reported in $94 \%$ (23\% hypogeusia, $45 \%$ ageusia, and $26 \%$ dysgeusia) (Beltran-Corbellini et al. 2020). As reported, the disorders pertaining to loss of smell and taste had an average duration of $7.1 \pm 3.1$ days. A European study conducted at multiple centers on 417 cases with mild-to-moderate COVID-19 disease revealed a similarly higher frequency (86\%) of patients suffering from olfactory dysfunction, with $20 \%$ and $80 \%$ of the patients manifesting hyposmia and anosmia, respectively (Lechien et al. 2020). Within 8 days of the onset of symptoms, $70 \%$ of the patients had recovered.

There have been suggestions that gustatory or olfactory dysfunction can indicate neuroinvasion and offers a route to the cardiorespiratory centers in the medulla from the oropharynx or the nasopharynx. These suggestions are based on studies conducted on transgenic mice infected by SARS-CoV and expressing the human SARS virus receptor (ACE2). At present there is no evidence to support host entry through this pathway in humans (Netlandet al. 2008). The direct infection from the virus and the subsequent killing of the gustatory and olfactory neurons in many patients may seem highly unlikely due to the transient nature of the dysfunction (Galougahi et al. 2020). Of the Wuhan COVID-19 series, $11 \%$ of patients reportedly exhibited evidence of skeletal muscle injury, which is defined as skeletal muscle pain and creatine kinase $(\mathrm{CK})>200$ U/L (Mao et al. 2020). Patients with severe disease (19\%) exhibited injury more commonly than patients with non-severe disease $(5 \%)(\mathrm{p}<0.001)$. However, unfortunately, other than the presence of the associated muscle pain, there are virtually no clinical details available. Two subsequent reports point to the presence of rhabdomyolysis as a hallmark or a late complication of COVID-19 (Suwanwongse and Shabarek 2020; Jin and Tong 2020). One of the patients exhibited weakness along with limb pain, with peak myoglobin $>12,000 \mu \mathrm{g} / \mathrm{L}$ and CK of approximately $12,000 \mathrm{U} / \mathrm{L}$, while another patient reported peak CK of 13,581 U/L. Although the mechanism of the injury is still to be determined, no muscle biopsy was performed on either of the patients.

\section{Immunological Aspects of Pathogenic SARS-CoV-2 and Implications for Treatment of Neurological Complications}

Amongst the extremely confusing hallmarks of SARS-CoV-2 infection is that almost $80 \%$ of patients, especially young adults or children, either exhibit minor symptoms or are asymptomatic. Only $20 \%$ of COVID-19 patients experience notable symptoms of infection, with extremely varying degrees of harshness. However, a definitive understanding of SARSCoV-2 immunopathogenesis from the knowledge that we have gathered on SARS-CoV is elusive. The first line of defense for the suppression of various neurotropic viruses at the point of entry or distribution is the successful production of type I interferon (IFN) response. Suppression of the downstream signaling of type I IFN response by SARS-CoV occurs with the assistance of various mechanisms, which are closely related to the severity of the disease (Channappanavar and Perlman 2017). As there is overall genomic similarity of over $80 \%$ between SARS-CoV and SARS-CoV-2, and they both use the same receptor, it is reasonable to expect that the innate immune mechanisms involved in pathogenesis are almost identical for the two viruses. Multiple strategies have been developed by SARS-CoV to optimize its replication ability and to evade the innate immune response (Nelemans and Kikkert 2019), and it seems that the same strategies are used by SARS-CoV-2. To exercise any control over the replication of the virus without actually causing any immunopathogenic injury, it is important to accurately calibrate the response of the immune system in front of SARS-CoV-2. A significant role is played by the hyperinflammatory response in acute respiratory distress syndrome (ARDS), where in a subset comprising children, it can lead to the development of a multi-system inflammatory disorder such as Kawasaki disease (Bryce et al. 2020).

Elevated lung cytokine/chemokine levels along with the associated vascular leakage and lethal pneumonia results from rapid SARS-CoV replication and delay in IFN-I signaling, which is responsible for inflammatory monocyte-macrophage accumulation. This is in turn related to suboptimal T-cell response to SARS-CoV and reduction in the number of $\mathrm{T}$ cells (Channappanavar et al. 2016). Similar patterns were found in a study on 522 patients who were infected with COVID-19, which revealed that the total number of $\mathrm{T}$ cells, as well as $\mathrm{CD} 4^{+}$and $\mathrm{CD} 8^{+}$cells, were dramatically reduced, especially in patients who required ICU care. T-cell numbers were negatively correlated with serum IL-10, IL-6, and TNF- $\alpha$ concentrations. Conversely, patients who were in the period of disease resolution exhibited lowered serum IL-10, IL-6, and TNF- $\alpha$ levels as well as restored T-cell counts (Diao et al. 2020). These data were substantiated by other groups who witnessed a reduction in type I IFN response in patients 
who were severely affected (Qin et al. 2020; Trouillet-Assant et al. 2020). Moreover, there have been suggestions that delayed and reduced production of IFN- $\gamma$ ("too little too late") in the lungs and reduction in both CD4 and CD8 T cells can occur in combination, which may lead to viral injury by a reduction in the control of the replication of the virus and enhancement of pro-inflammatory cytokine upregulation, including IL-10, IL-6, and TNF- $\alpha$ ("cytokine storm"), and it may be the immune dysregulation as much or more than the direct viral infection that results in pulmonary epithelial cell injury. Similar mechanisms could be operative in the CNS (Pedersen and Ho 2020). Moreover, the probable mechanisms for the dysregulation of the immune system and whether they play any role in the neuropathogenesis of COVID-19 are unknown. Although there is still obscurity regarding the sources of cytokines that are found in the serum, it is possible that they can be produced by lung macrophages. As observed in the transgenic mouse model of SARS-CoV, IL- 6 can also come from neurons that are infected (Netland et al. 2008). In turn, lymphocytopenia can be caused by higher levels of circulating cytokines. TNF- $\alpha$, which is a pro-inflammatory cytokine that interacts with the receptor TNFR1, can cause T-cell apoptosis and is reported to have increased expression in aged T cells (Aggarwal et al. 1999; Gupta et al. 2005). IL-6 contributes to host defense in response to infections, exhibiting both pro- and anti-inflammatory properties.
However, a key pathological role has been demonstrated through the continual synthesis of IL-6 in chronic infection and inflammation (Gabay 2006; Jones and Jenkins 2018). IL-10, which is an inhibitory cytokine and prevents the proliferation of $\mathrm{T}$ cells, can also lead to the exhaustion of $\mathrm{T}$ cells. Moreover, levels of the programmed cell death receptor 1 (PD-1) and T-cell immunoglobulin mucin-3 (Tim3 ) exhaustion markers are observed in the T cells of patients who have been affected by COVID-19 (Diao et al. 2020). Conversely, the cellular immune response to SARS-CoV-2 is weakened by the reduced number of $\mathrm{CD}^{+}$and $\mathrm{CD} 4^{+} \mathrm{T}$ lymphocytes in very extreme cases, thereby creating the scope for further replication of the virus. The use of corticosteroids can significantly compound this problem. Of note, in a study conducted on convalescent patients with SARS-CoV, responses of $\mathrm{CD}^{+} \mathrm{T}$ cells were extremely regular and of greater magnitude in comparison to $\mathrm{CD} 4^{+} \mathrm{T}$ cells $(\mathrm{Li}$ et al. 2008). Finally, histological features that indicate secondary hemophagocytic lymphohistiocytosis (sHLH) were suggested through an autopsy series of COVID-19 patients. This condition is also known as macrophage activation syndrome, which is characterized by an imbalance in adaptive and innate immune responses, with aberrant activation of macrophages and a blunted adaptive immune response (Bryce et al. 2020). This dysregulated immune response may play a role in the pathogenesis of COVID-19 encephalopathy. An increase in
Fig. 5 Putative mechanisms underlying SARS-CoV-2 neuropathogenesis: SARSCoV-2 neuropathogenic effects are likely multifactorial, including, involvement of the peripheral nervous system (PNS) and muscle, direct neuroinvasion of the central nervous system (CNS), manifestations of systemic disease, as well as through a post-infectious, immunemediated mechanism. MOF: multi-organ failure. Phi ( $\boldsymbol{\varphi})$ denotes direct evidence of viral invasion (RT-PCR +, biopsy); star ( $\star$ denotes CNS inflammation (CSF pleocytosis and proteinoracchia) with no evidence of direct viral infection of CNS

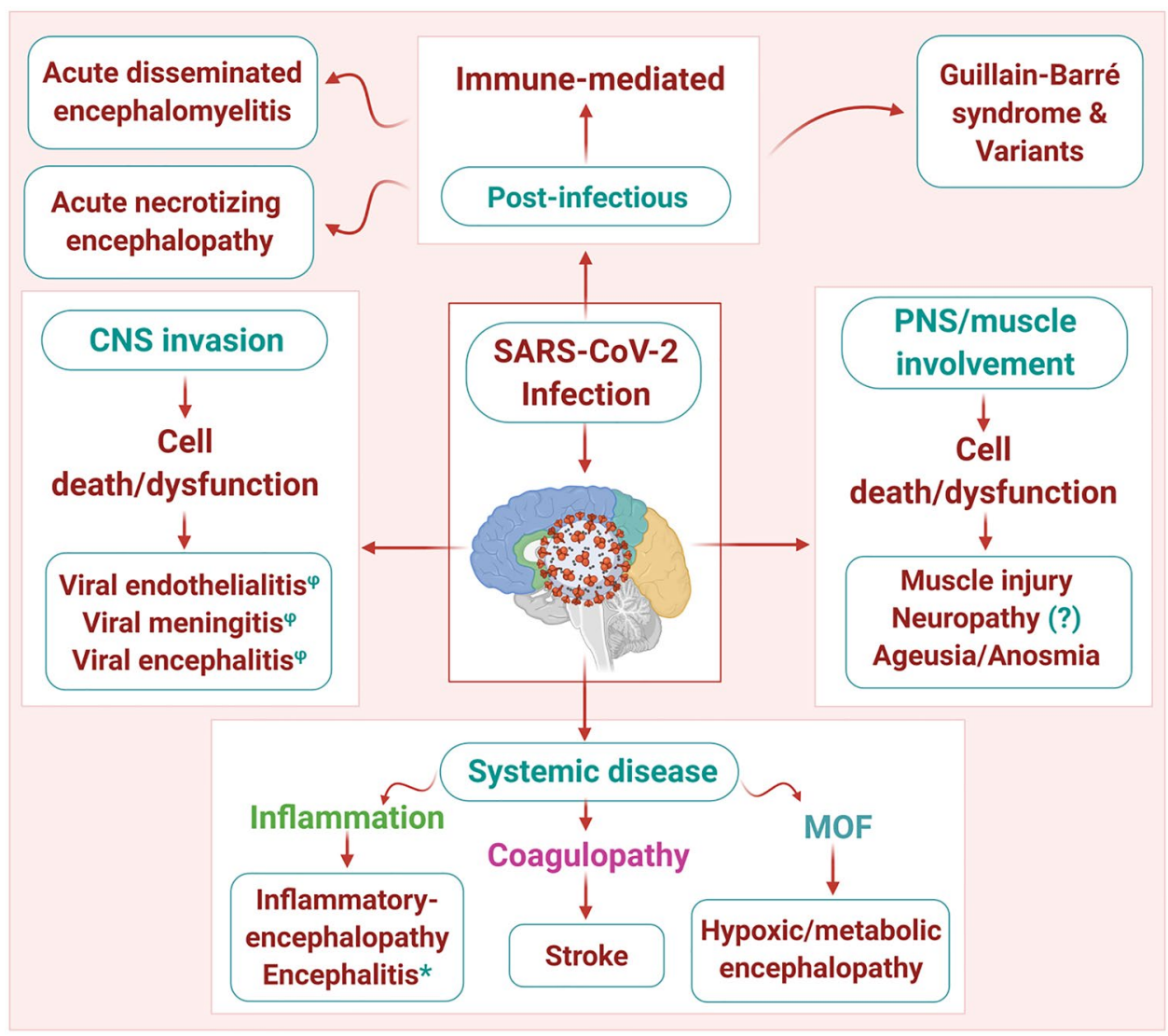


the levels of circulating pro-inflammatory cytokines can lead to alteration and confusion of consciousness. However, the elimination of virus-infected cells in the brain may not be possible due to the weakened T-cell response, which may further lead to neurological dysfunction. There is an urgent need of carefully conducted studies on T-cell response to SARS-CoV-2 and the CSF cytokine profile, along with postmortem studies, including the muscle tissues and CNS, to better understand the neuropathogenesis of COVID19. These studies will help to gain a better understanding of whether the therapeutic strategies which are intended to completely stop pro-inflammatory cytokines (including the IL-6 inhibitors sarilumab and tocilizumab) can exert any significant positive effect on the encephalopathy, or whether corticosteroids are contraindicated where the adaptive cellular immune response to the viruses has been dampened. As efforts are being made to identify medications that can counter the deleterious inflammatory stage that is triggered by SARS-CoV-2, the outcomes of COVID-19 in patients exhibiting neurological diseases such as myasthenia gravis or MS who have been treated with immunomodulatory therapies can offer valuable lessons. While our understanding of the biological complexity of SARS-CoV-2 is still only in the nascent stage, it is certainly evident that a significant threat is posed by COVID-19 to the entire nervous system via the multifactorial pathogenic mechanisms and worldwide prevalence (Fig.5). As we are striving for a vaccine or a cure to counter the virus, an important role will be played by neurologists in diagnosing, investigating, and treating several of the neurological manifestations of COVID-19 (Table 1) (McArthur 2020).

\section{Mechanisms Linking COVID-19 and Neurological Manifestations}

The involvement of the human nervous system has been supported by several lines of evidence in MERS, SARS, and SARS-CoV-2 (COVID-19). It is still difficult to determine how the overall pathophysiology is related to the varied

Table 1 SARS-CoV-2 infection and neurological conditions

\begin{tabular}{|c|c|c|c|c|}
\hline S. no. & Neurological ailment & Pathogenesis & Clinical manifestations & $\begin{array}{l}\text { Diagnostic testing in support of } \\
\text { neurological ailment }\end{array}$ \\
\hline 1 & Muscle injury & Myopathy or myositis? & Myalgia & $\begin{array}{l}\text { Elevated creatine phosphokinase } \\
\text { level }\end{array}$ \\
\hline 2 & $\begin{array}{r}\text { Acute disseminated } \\
\text { encephalomyelitis }\end{array}$ & Post-infectious & $\begin{array}{l}\text { Acute neurological symptoms } \\
\text { and headache }\end{array}$ & $\begin{array}{l}\text { MRI: Hyperintense FLAIR } \\
\text { lesions with variable } \\
\text { enhancement }\end{array}$ \\
\hline 3 & Guillain-Barré syndrome (GBS) & Post-infectious & Flaccid muscle weakness & $\begin{array}{l}\text { EMG/NCS: Abnormal } \\
\text { CSF SARS-CoV-2 RT-PCR: NEG } \\
\text { CSF: Increased protein, nl WBC }\end{array}$ \\
\hline 4 & Encephalitis & Neuroinflammation & $\begin{array}{l}\text { CNS dysfunction and impaired } \\
\text { mental state }\end{array}$ & $\begin{array}{l}\text { CSF SARS-CoV-2 RT-PCR: NEG } \\
\text { CSF: Pleocytosis \& elev. Pro } \\
\text { EEG: Abnormal (slow, + focal) } \\
\text { MRI: Nonspecific (? WM } \\
\text { changes) }\end{array}$ \\
\hline 5 & Encephalopathy & $\begin{array}{l}\text { Endothelialitis, multiple } \\
\text { organ failure, systemic } \\
\text { inflammation, and hypoxemia }\end{array}$ & Impaired mental state & $\begin{array}{l}\text { CSF SARS-CoV-2 RT-PCR: NEG } \\
\text { CSF: nl cells and Pro } \\
\text { EEG: Abnormal (slow) } \\
\text { MRI: Nonspecific }\end{array}$ \\
\hline 6 & Viral encephalitis & $\begin{array}{l}\text { Brain parenchymal } \\
\text { neuroinvasion }\end{array}$ & $\begin{array}{l}\text { CNS dysfunction and impaired } \\
\text { mental state }\end{array}$ & $\begin{array}{l}\text { Brain Tissue: POS (Ag or RNA) } \\
\text { CSF SARS-CoV-2 RT-PCR: POS } \\
\text { CSF: Pleocytosis and elev. Pro } \\
\text { MRI: New abnormality } \\
\text { EEG: Abnormal (slow, }+ \text { focal) }\end{array}$ \\
\hline 7 & Ageusia/anosmia & $\begin{array}{l}\text { ? Peripheral vs. central } \\
\text { neuroinvasion }\end{array}$ & $\begin{array}{l}\text { Olfactory/ taste loss or } \\
\text { impairment }\end{array}$ & $\begin{array}{l}\text { Test reports showed abnormalities } \\
\text { in smell or taste }\end{array}$ \\
\hline 8 & Stroke & Coagulopathy & Focal motor or sensory loss & $\begin{array}{l}\text { MRI: Ischemia or bleed, } \\
\text { abnormal coagulation factors } \\
\text { increased inflammatory markers }\end{array}$ \\
\hline 9 & Viral meningitis & Subarachnoid invasion & Nuchal rigidity and headache & $\begin{array}{l}\text { CSF SARS-CoV-2 RT PCR: POS } \\
\text { CSF: Pleocytosis \& elev. Pro } \\
\text { MRI: Meningeal enhancement }\end{array}$ \\
\hline
\end{tabular}


neurological features, that is, whether they result indirectly or directly from viral infections, or arise from further mechanisms such as sepsis, hypoxia, or MOF. One of the potential available mechanisms is through the immunerelated pathway. It appears that COVID-19 possesses a pivotal immune component, as various studies have reported findings such as increased C-reactive protein (CRP) levels and lymphopenia in patients affected by the disease (Huang et al. 2019; Chen et al. 2020c; Mehta et al. 2020). One uncommon but fatal complication in COVID-19 that has recently gained significant attention, especially in those who exhibit severe disease, is cytokine storm syndrome, which includes secondary hemophagocytic lymphohistiocytosis (sHLH) (Mehta et al. 2020). Therefore, patients with severe COVID19 are constantly monitored for increased levels of ferritin, which is indicative of hyperinflammation. It is worth noting that one of the studies reported lower platelet counts and lower lymphocyte levels in those COVID-19 patients who presented CNS symptoms as compared to patients who did not present with CNS involvement (Mao et al. 2020; Li et al. 2020a, b). An increase in D-dimer levels, which is a marker of endogenous fibrinolysis and a hypercoagulable state, has also been reported in patients with severe disease and can possibly explain why the development of acute cerebrovascular disease is extremely common in patients exhibiting symptoms (Mao et al. 2020; Li et al. 2020a, b). There have been suggestions that the risk of acute cerebrovascular disease can be reduced through the early targeting of anti-inflammatory pathways ( $\mathrm{Li}$ et al. 2020a, b).

\section{Concluding Remarks}

The neurological connection in SARS-CoV-2 and other $\mathrm{CoV}$ infections is an ever-expanding area of interest for neuroscientists. There are several reports that advocate the neurological manifestations of SARS-CoV-2 and COVID19 pathogenesis. Most importantly, numerous mechanisms, including post-infectious immune-mediated processes, direct virus infection of the CNS, and virus-induced hyperinflammation, are commonly involved in SARS-CoV-2 neuropathology. Furthermore, CNS and PNS diseases such as Guillain-Barre syndrome and its variants, dysfunction of taste and smell, muscle injury, hemorrhagic and ischemic stroke, encephalitis, and meningitis are reported to be associated with SARS-CoV-2 infections. Needless to say, what we have learned is just the tip of the iceberg, and much remains to be understood in this domain for proper therapeutic intervention. Finally, improving our knowledge of SARS-CoV-2 neurobiology could enhance our understanding of neurological impairments with probable viral associations such as MS and viral encephalitis.
Author contributions SKJ, DKC, GG, and KD collected the articles and initiated the draft of the review. HD, SKS, SDS, SB, NK, MJ, RJ, SM, RK, DK, VKG, JR, KKK, and SKS contributed to revision of the review. NKJ and SO edited the review and performed proofreading and final editing. All authors have read and approved the final manuscript.

Funding There are no relevant funding sources to report.

\section{Compliance with ethical standards}

Conflict of Interest The authors declare that they have no conflict of interest.

Consent for publication: All co-authors have given their consent for publication.

\section{References}

Abdennour L, Zeghal C, Deme M, Puybasset L (2012) Interaction brain-lungs. Ann Fr Anesth Reanim 31(6):e101-107

Aggarwal S, Gollapudi S, Gupta S (1999) Increased TNF-alpha-induced apoptosis in lymphocytes from aged humans: changes in TNFalpha receptor expression and activation of caspases. J Immunol 162:2154-2161

Algahtani H, Subahi A, Shirah B (2016) Neurological complications of Middle East respiratory syndrome coronavirus: a report of two cases and review of the literature. Case Rep Neurol Med 2016:3502683

Arabi YM, Harthi A, Hussein J, Bouchama A, Johani S, Hajeer AH (2015) Severe neurologic syndrome associated with Middle East respiratory syndrome corona virus (MERS-CoV). Infection 43(4):495-501

Arbour N (1999) Persistent infection of human oligodendrocytic and neuroglial cell lines by human coronavirus 229E. J Virol 73(4):3326-3337

Arbour N (2000) Neuroinvasion by human respiratory coronaviruses. J Virol 74(19):8913-8921

Avula A (2020) COVID-19 presenting as stroke. Brain Behav Immun $87: 115-119$

Bagheri SHR, Asghari AM, Farhadi M, Shamshiri AR, Kabir A, Kamrava SK (2020) Coincidence of COVID-19 epidemic and olfactory dysfunction outbreak. medRxiv 03:20041889

Baig AM, Khaleeq A, Ali U, Syeda H (2020) Evidence of the COVID19 virus targeting the CNS: tissue distribution, host-virus interaction, and proposed neurotropicmechanisms. ACS Chem Neurosci 11(7):995-998

Baud D, Qi X, Nielsen-Saines K, Musso D, Pomar L, Favre G (2020) Real estimates of mortality following COVID-19 infection. Lancet Infect Dis 20:773

Beltran-Corbellini A, Chico-Garcia JL, Martinez-Poles J (2020) Acuteonset smell and taste disorders in the context of Covid-19: a pilot multicenter PCR-based case-control study. Eur J Neurol 0:1-4. https://doi.org/10.1111/ene.14273

Berth SH, Leopold PL, Morfini GN (2009) Virus-induced neuronal dysfunction and degeneration. Front Biosci (Landmark Ed)14:5239-5259. https://doi.org/10.2741/3595

Bohmwald K, Galvez NMS, Rios M, Kalergis AM (2018) Neurologic alterations due to respiratory virus infections. Front Cell Neurosci 12:386

Boucher A (2007) Long-term human coronavirus-myelin cross-reactive T-cell clones derived from multiple sclerosis patients. Clin Immunol 123(3):258-267 
Brann DH, Tsukahara T, Weinreb C, Lipovsek M, Van den Berge K, Gong B (2020) Non-neuronal expression of SARS-CoV-2 entry genes in the olfactory system suggests mechanisms underlying COVID-19-associated anosmia. Sci Adv 6(31):1-28

Bryce C, Grimes Z, Pujadas E (2020) Pathophysiology of SARS-CoV-2: targeting of endothelial cells renders a complex disease with thrombotic microangiopathy and aberrant immune response. The Mount Sinai COVID-19 autopsy experience. medRxiv. https://doi. org/10.1101/2020.05.18.20099960

Channappanavar R, Fehr AR, Vijay R (2016) Dysregulated type I interferon and inflammatory monocyte-macrophage responses cause lethal pneumonia in SARS-CoV-infected mice. Cell Host Microbe 19:181-193

Channappanavar R, Perlman S (2017) Pathogenic human coronavirus infections: causes and consequences of cytokine storm and immunopathology. Semin Immunopathol 39:529-539

Chao CC, Tsai LK, Chiou YH, Tseng MT, Hsieh ST, Chang SC (2003) Peripheral nerve disease in SARS: report of a case. Neurology 61(12):1820-1821

Chen R, Wang K, Yu J, Chen Z, Wen C, Xu Z (2020a) The spatial and cell-type distribution of SARS-CoV-2 receptor ACE2 in human and mouse brain. $2020 \mathrm{https}: / / \mathrm{www}$. biorxiv.org/content/https://doi. org/10.1101/2020.04.07.030650v1

Chen C, Zhang XR, Ju ZY, He WF (2020) Advances in the research of cytokinestorm mechanism induced by Corona Virus Disease 2019 and the corresponding immunotherapies. Zhonghua Shao Shang Za Zhi 36:E005

Chen G, Wu D, Guo W, Cao Y, Huang D, Wang H (2020) Clinical and immunological features of severe and moderate coronavirus disease 2019. J Clin Invest 130(5):2620-2629

Chen N (2020) Epidemiological and clinical characteristics of 99 cases of 2019 novel coronavirus pneumonia in Wuhan, China: a descriptive study. Lancet 395(10223):507-513

Desforges M, Le Coupanec A, Dubeau P, Bourgouin A, Lajoie L, Dube M, Talbot PJ (2019) Human coronaviruses and other respiratory viruses: underestimated opportunistic pathogens of the central nervous system? Viruses 12(1):14

Desforges M, Le Coupanec A, Brison E, Meessen-Pinard M, Talbot PJ (2014) Neuroinvasive and neurotropic human respiratory coronaviruses: potential neurovirulent agents in humans. Adv Exp Med Biol 807:75-96. https://doi.org/10.1007/978-81-322-1777-06

Diao B, Wang C, Tan Y, Chen X, Liu Y, Ning L, Chen L, Li M, Liu Y, Wang G, Yuan Z, Feng Z, Zhang Y, Wu Y, Chen Y (2020) Reduction and functional exhaustion of $T$ cells in patients with coronavirus disease 2019 (COVID-19). Front Immunol 11:827. https://doi.org/10.3389/fimmu.2020.00827

Dobbs MR (2011) Toxic encephalopathy. Semin Neurol 31(2):184-193

Doobay MF, Talman LS, Obr TD, Tian X, Davisson RL, Lazartigues E (2007) Differential expression of neuronal ACE2 in transgenic mice with overexpression of the brain renin-angiotensin system. Am J Physiol Regul Integr Comp Physiol 292(1):R373-R381. https://doi.org/10.1152/ajpregu.00292.2006

Dube M, CoupanecA Le, Wong AHM, Rini JM, DesforgesM TPJ (2018) Axonal transport enables neuron-to-neuron propagation of human coronavirus OC43. J Virol 92(17):e00404-e418. https://doi. org/10.1128/JVI.00404-18

Duffy L, O'Reilly SC (2016) Toll-like receptors in the pathogenesis of autoimmune diseases: recent and emerging translational developments. Immunotargets Ther 5:69-80

Elkind MS (2007) Why now? Moving from stroke risk factors to stroke triggers. CurrOpinNeurol 20(1):51-57

Ellul M, Solomon T (2018) Acute encephalitis - diagnosis and management. Clin Med (Lond) 18(2):155-159

Fehr AR, Perlman S (2015) Coronaviruses: an overview of their replication and pathogenesis. Methods Mol Biol 1282:1-23
Fodoulian L, Tuberosa J, Rossier D, Landis BN, Carleton A, Rodriguez I (2020) SARS-CoV-2 receptor and entry genes are expressed by sustentacular cells in the human olfactory neuroepithelium. bioRxiv 2020(03):31.013268

Fu Y, Cheng Y, Wu Y (2020) Understanding SARS-CoV-2-Mediated InflammatoryResponses: From Mechanisms to Potential Therapeutic Tools. Virologica Sinica 35(3):266-271

Gabay C (2006) Interleukin-6 and chronic inflammation. Arthritis Res Ther 8:S3

Galougahi MK, Ghorbani J, Bakhshayeshkaram M (2020) Olfactory bulb magnetic resonance imaging in SARS-CoV-2-induced anosmia: the first report. Acad Radiol 27(6):892-893. https:// doi.org/10.1016/j.acra.2020.04.002

Gerna G (2007) Human respiratory coronavirus HKU1 versus other coronavirus infections in Italian hospitalised patients. J Clin Virol 38(3):244-250

Giacomelli A, Pezzati L, Conti F, Bernacchia D, Siano M, Oreni L (2020) Self-reported olfactory and taste disorders in patients with severe acute respiratory coronavirus 2 infection: a cross-sectional study. Clin Infect Dis 71(15):889-890

Gu J, Gong E, Zhang B, Zheng J, Gao Z, Zhong Y (2005) Multiple organ infection and the pathogenesis of SARS. J Exp Med 202(3):415-424

Guo J (2020) Coronavirus disease 2019 (COVID-19) and cardiovascular disease: a viewpoint on the potential influence of angiotensinconverting enzyme Inhibitors/Angiotensin receptor blockers on onset and severity of severe acute respiratory syndrome coronavirus 2 infection. J Am Heart Assoc 9(7):e016219

Guo YR, Cao QD, Hong ZS, Tan YY, Chen SD, Jin HJ (2020) The origin, transmission and clinical therapies on coronavirus disease 2019 (COVID-19) outbreak- an update on the status. Mil Med Res 7(1):11

Gupta S, Bi R, Kim C, Chiplunkar S, Yel L, Gollapudi S (2005) Role of NF-kappaBsignaling pathway in increased tumor necrosis factoralpha-induced apoptosis of lymphocytes in aged humans. Cell Death Differ 12:177-183

Guan WJ, Ni ZY, Hu Y, Liang WH, Ou CQ, He JX (2020) Clinical characteristics of coronavirus disease 2019 in China. N Engl J Med 382:1708-1720

Gutierrez-Ortiz C, Mendez A, Rodrigo-Rey S (2020) Miller Fisher syndrome and polyneuritis cranialis in COVID-19. Neurology 95(9):408

Helms J, Kremer S, Merdji H, Clere-Jehl R, Schenck M, Kummerlen $\mathrm{C}$ (2020) Neurologic features in severe SARS-CoV-2 infection. N Engl J Med 382:23

Houtman JJ, Hinze HC, Fleming JO (1995) Demyelination induced by murine coronavirus JHM infection of congenitally immunodeficient mice. In: Talbot PJ, Levy GA (ed) Corona- and Related Viruses: Current Concepts in Molecular Biology and Pathogenesis. Springer US; Boston, MA: pp 159-163

Huang C, Wang Y, Li X, Ren L, Zhao J, Hu Y (2020) Clinical features of patients infected with 2019 novel coronavirus in Wuhan. China Lancet 395(10223):497-506

Hung EC, Chim SS, Chan PK, Tong YK, Ng EK, Chiu RW (2003) Detection of SARS coronavirus RNA in the cerebrospinal fluid of a patient with severe acute respiratory syndrome. Clin Chem 49(12):2108-2109

Hwang CS (2006) Olfactory neuropathy in severe acute respiratory syndrome: report of A case. Acta Neurol Taiwan 15(1):26-28

Jacomy H, Fragoso G, Almazan G, Mushynski WE, Talbot PJ (2006) Human coronavirus OC43 infection induces chronic encephalitis leading to disabilities in BALB/C mice. Virology 349:335-346

Jin M, Tong Q (2020) Rhabdomyolysis as potential late complication associated with COVID-19. Emerg Infect Dis 26(7):1618-1620

Jones SA, Jenkins BJ (2018) Recent insights into targeting the IL-6 cytokine family in inflammatory diseases and cancer. Nat Rev Immunol 18:773-789 
Karimi N, Razavi AS, Rouhani N (2020) Frequent convulsive seizures in an adult patient with COVID-19: a case report. Iran Red Crescent Med J 22(3):e102828

Kim JE, Heo JH, Kim HO, Song SH, Park SS, Park TH, Ahn JY, Kim MK, Choi JP (2017) Neurological complications during treatment of Middle East respiratory syndrome. J Clin Neurol 13(3):227-233

Kim W-K, Corey S, Alvarez X, Williams K (2003) Monocyte/macrophage traffic in HIV and SIV encephalitis. J LeukocBiol 74(5):650-656. https://doi.org/10.1189/jlb.0503207

Klein RS, Garber C, Howard N (2017) Infectious immunity in the central nervous system and brain function. Nat Immunol 18(2):132-141

Koyuncu OO, Hogue IB, Enquist LW (2013) Virus infections in the nervous system. Cell Host Microbe 13(4):379-393

Lau KK, Yu WC, Chu CM, Lau ST, Sheng B, Yuen KY (2004) Possible central nervous system infection by SARS coronavirus. Emerg Infect Dis 10(2):342-344

Leber AL, Everhart K, Balada-Llasat JM, Cullison J, Daly J, Holt S (2016) Multicenter evaluation of BioFire FilmArray meningitis/ encephalitis panel for detection of bacteria, viruses, and yeast in cerebrospinal fluid specimens. J Clin Microbiol 54(9):2251-2261

Lechien JR, Chiesa-Estomba CM, De Siati DR, Horoi M, Le Bon SD, Rodriguez A (2020) (Olfactory and gustatory dysfunctions as a clinical presentation of mild-to-moderate forms of the coronavirus disease (COVID-19): a multicenter European study. Eur Arch Otorhinolaryngol 6:1-11

Lew TW (2003) Acute respiratory distress syndrome in critically ill patients with severe acute respiratory syndrome. JAMA 290(3):374-380

Li CK, Wu H, Yan H, Ma S, Wang L, Zhang M, Tang X, Temperton NJ, Weiss RA (2008) T cell responses to whole SARS coronavirus in humans. J Immunol 181:5490-5500

Li YC, Bai W, Hashikawa T (2020) The neuroinvasive potential of SARS-CoV2 may be at least partially responsible for the respiratory failure of COVID-19 patients. J Med Virol 92(6):552-555

Li Y, Fu L, Gonzales DM, Lavi E (2004) Coronavirus neurovirulence correlates with the ability of the virus to induce proinflammatory cytokine signals from astrocytes and microglia. J Virol 78(7):3398-3406

Li Y, Wang M, Zhou Y, Chang J, Xian Y, Mao L (2020). Acute Cerebrovascular Disease Following COVID-19: A Single Center, Retrospective, Observational Study. SSRN 2020; Available at SSRN: https://ssrn.com/abstract $=3550025$

Libbey JE, Lane TE, Fujinami RS (2014) Axonal pathology and demyelination in viral models of multiple sclerosis. Discov Med 18(97):79-89

Lin L, Zheng LJ, Zhang LJ (2018) Neuroinflammation, gut microbiome, and Alzheimer's Disease. Mol Neurobiol 55:8243-8250

Lukassen S, Chua RL, Trefzer T, Kahn NC, Schneider MA, Muley $\mathrm{T}$ (2020) SARS-CoV-2 receptor ACE2 and TMPRSS2 are primarily expressed in bronchial transient secretory cells. EMBO J 39(10):e105114

Mao L, Jin H, Wang M, Hu Y, Chen S, He Q, Chang J, Hong C, Zhou Y, Wang D, Miao X, Li Y, Hu B (2020) Neurologic manifestations of hospitalized patients with coronavirus disease 2019 in Wuhan. China Jama Neurol 77(6):1-9

Matsuda K, Park CH, Sunden Y, Kimura T, Ochiai K, Kida H, Umemura $\mathrm{T}$ (2004) The vagus nerve is one route of transneural invasion for intranasally inoculated influenza a virus in mice. Vet Pathol 41(2):101-107. https://doi.org/10.1354/vp.41-2-101

McArthur JC (2020) The path forward: academic neurology responds to COVID-19. Ann Neurol 87(6):789-793

McCray PB Jr, PeweL W-L, Hickey M, Manzel L, Shi L, Netland J, Jai HP, Halabi C, Sigmund CD, Meyerholz DK, Kirby P, Look DC,
Perlman S (2007) Lethal infection of K18-hACE2 mice infected with severe acute respiratory syndrome coronavirus. J Virol 81(2):813-821. https://doi.org/10.1128/JVI.02012-06

Mehta P, McAuley DF, Brown M, Sanchez E, Tattersall RS, Manson JJ (2020) COVID-19: consider cytokine storm syndromes and immunosuppression. Lancet 395(10229):1033-1034

Menni C, Valdes A, Freydin MB, Ganesh S, El-Sayed Moustafa J, Visconti A (2020) Loss of smell and taste in combination with other symptoms is a strong predictor of COVID-19 infection. medRxiv 2020(04):20048421

Miller AJ, Arnold AC (2019) The renin-angiotensin system in cardiovascular autonomic control: recent developments and clinical implications. Clin Auton Res 29(2):231-243

Miller KD, Schnell MJ, Rall GF (2016) Keeping it in check: chronic viral infection and antiviral immunity in the brain. Nat Rev Neurosci 17:766-776

Mizuguchi M, Yamanouchi H, Ichiyama T, Shiomi M (2007) Acute encephalopathy associated with influenza and other viral infections. Acta Neurol Scand Suppl 186:45-56

Morfopoulou S (2016) Human coronavirus OC43 associated with fatal encephalitis. N Engl J Med 375(5):497-498

Mori I (2015) Transolfactory neuroinvasion by viruses threatens the human brain. Acta Virol 59(4):338-349

Moriguchi T, Harii N, Goto J, Harada D, Sugawara H, Takamino J (2020) A first case of meningitis/encephalitis associated with SARS-Coronavirus-2. Int J Infect Dis 94:55-58

Muhammad S, Haasbach E, Kotchourko M, Strigli A, Krenz A, Ridder DA, VogelAB, Marti HH, Al-Abed Y, Planz O, Schwaninger M (2011) Influenza virus infectionaggravates stroke outcome. Stroke 42(3):783-91

Murray RS (1992) Detection of coronavirus RNA and antigen in multiple sclerosis brain. Ann Neurol 31(5):525-533

Nelemans T, Kikkert M (2019) Viral innate immune evasion and the pathogenesis of emerging RNA virus infections. Viruses 11(10):961

Netland J, Meyerholz DK, Moore S, Cassell M, Perlman S (2008) Severe acute respiratory syndrome coronavirus infection causes neuronal death in the absence of encephalitis in mice transgenic for human ACE2. J Virol 82(15):7264-7275

Nguyen TP, Taylor RS (2020) Guillain Barre Syndrome. StatPearls Publishing

Nicholls JM, Butany J, Poon LLM, Chan KH, Beh SL, Poutanen S, Malik Peiris JS, Wong M (2006) Time course and cellular localization of SARS-CoV nucleoprotein and RNA in lungs from fatal cases of SARS. PLoS Med 3(2):e27. https://doi.org/10.1371/journal. pmed.0030027

Oxley TJ, Mocco J, Majidi S, Kellner CP, Shoirah H, Singh PI, De Leacy RA, Shirematsu T, Ladner TR (2020) Large-vessel stroke as a presenting feature of Covid-19 in the young. N Engl J Med 382(20):e60

Panigada M, Bottino N, Tagliabue P, Grasselli G, Novembrino C, Chantarangkul V, Pesenti A, Peyvandi F, Tripodi A (2020) Hypercoagulability of COVID-19 patients in intensive care unit: A report of thromboelastography findings and other parameters of hemostasis. J ThrombHaemost 18(7):1738-1742

Paniz-Mondolfi A, Bryce C, Grimes Z, Gordon RE, Reidy J, Lednicky J, Sordillo EM, Fowkes M (2020) Central nervous system involvement by severe acute respiratory syndrome coronavirus-2 (SARS-CoV-2). J Med Virol 92(7):699 -702. https://doi.org/10.1002/jmv.25915

Pedersen SF, Ho YC (2020) SARS-CoV-2: a storm is raging. J Clin Invest 130:2202-2205

Powers WJ (2019) Guidelines for the early management of patients with acute ischemic stroke: 2019 update to the 2018 guidelines for the early management of acute ischemic stroke: a guideline for healthcare professionals from the American Heart Association/ American Stroke Association. Stroke 50(12):e344-e418 
Poyiadji N, Shahin G, Noujaim D, Stone M, Patel S, Griffith B (2020) COVID-19-associated acute hemorrhagic necrotizing encephalopathy: Imaging features. Radiology 296(2):E119-120

Qin C, Zhou L, Hu Z, Zhang S, Yang S, Tao Y, Xie C, Ma K, Shang K, Wang W, Tian DS (2020) Dysregulation of immune response in patients with COVID-19 in Wuhan. China Clin Infect Dis 71(15):762-768

Reinhold AK, Rittner HL (2017) Barrier function in the peripheral and central nervous system-a review. Pflugers Arch 469(1):123-134

Saad M, Omrani AS, Baig K, Bahloul A, Elzein F, Matin MA (2014) Clinical aspects and outcomes of 70 patients with Middle East respiratory syndrome coronavirus infection: a single-center experience in Saudi Arabia. Int J Infect Dis 29:301-306

Sankowski R, Mader S, Valdes-Ferrer SI (2015) Systemic inflammation and the brain: novel roles of genetic, molecular, and environmental cues as drivers of neurodegeneration. Front Cell Neurosci 9(28):28. https://doi.org/10.3389/fncel.2015.00028

Savarin C (2008) Memory CD4+ T-cell-mediated protection from lethal coronavirus encephalomyelitis. J Virol 82(24):12432-12440

Sedaghat Z, Karimi N (2020) Guillain Barre syndrome associated with COVID-19 infection: a case report. J Clin Neurosci 76:233-235

Spiegel M, Schneider K, Weber F, Weidmann M, Hufert FT (2006) Interaction of severe acute respiratory syndrome-associated coronavirus with dendritic cells. J Gen Virol 87(Pt 7):1953-1960. https://doi.org/10.1099/vir.0.81624-0

Stewart JN, Mounir S, Talbot PJ (1992) Human coronavirus gene expression in the brains of multiple sclerosis patients. Virology 191(1):502-505

Sun N (1995) Activation of astrocytes in the spinal cord of mice chronically infected with a neurotropic coronavirus. Virology 213(2):482-493

Swanson PA 2nd, McGavern DB (2015) Viral diseases of the central nervous system. Current Opinion in Virology 11:44-54

Suwanwongse K, Shabarek N (2020) Rhabdomyolysis as a presentation of 2019 Novel Coronavirus Disease. Cureus 12(4):e7561

Tauber SC, Eiffert H, Bruck W, Nau R (2017) Septic encephalopathy and septic encephalitis. Expert Rev Anti Infect Ther 15(2):121-132

Toscano G, Palmerini F, Ravaglia S, Ruiz L, Invernizzi P, Cuzzoni MG, Franciotta D, Baldanti F, Daturi R, Postorino P, Cavallini A, Micieli G (2020) Guillain-Barré syndrome associated with SARS-CoV-2. N Engl J Med 382:2574-2576

Trojanowicz B, Ulrich C, Kohler F, Bode V, Seibert E, Fiedler R, Girndt M (2017) Monocytic angiotensin-converting enzyme 2 relates to atherosclerosis in patients with chronic kidney disease. Nephrol Dial Transplant 32(2):287-298

Trouillet-Assant S, Viel S, Gaymard A, Pons S, Richard J-C, Perret M, Villard M (2020) Type I IFN immunoprofiling in COVID-19 patients. J Allergy Clin Immunol 146(1):206-208

Tsai LK, Hsieh ST, Chang YC (2005) Neurological manifestations in severe acute respiratory syndrome. Acta Neurol Taiwan 14(3):113-119

Turner AJ, Hiscox JA, Hooper NM (2004) ACE2: from vasopeptidase to SARS virusreceptor. Trends Pharmacol Sci 25(6):291-294

Umapathi T, Kor AC, Venketasubramanian N, Lim CC, Pang BC, Yeo TT (2004) Large artery ischaemic stroke in severe acute respiratory syndrome (SARS). J Neurol 251(10):1227-1231

Unni SK, Ruzek D, Chhatbar C, Mishra R, Johri MK, Singh SK (2011) Japanese encephalitis virus: from genome to infectome. Microbes Infect 13(4):312-321

Wan SX, Yi QJ, Fan SB, Lv JL, Zhang XX, Guo L (2020). Characteristics of lymphocyte subsets and cytokines in peripheral blood of 123 hospitalized patients with 2019 novel coronavirus pneumonia (NCP). MedRxiv 2020.02.10.20021832

Wang X, XuW, Hu G, Xia S, Sun Z, Liu Z, Xie Y, Zhang S, Lu L (2020a) SARS-CoV-2 infects $\mathrm{T}$ lymphocytes through its spike proteinmediated membrane fusion. Cell Mol Immunol 1-3. https://doi. org/10.1038/s41423-020-0424-9

Wang Y, Wang Y, Chen Y, Qin Q (2020b) Unique epidemiological and clinical features of the emerging 2019 novel coronavirus pneumonia (COVID-19) implicate special control measures. J Med Virol 92(6):568-576

Wang R, Pan M, Zhang X, Fan X, Han M, Zhao F (2020c) Epidemiological and clinical features of 125 Hospitalized Patients with COVID-19 in Fuyang, Anhui, China. Int J Infect Dis 95:421-428

Wang D, Hu B, Hu C, Zhu F, Liu X, Zhang J, Wang B, Xiang H, Cheng Z, Xiong Y, Zhao Y, Li Y, Wang X, Reng Z (2020d) Clinical characteristics of 138 hospitalized patients with 2019 novel coronavirus-infected pneumonia in Wuhan. China JAMA 323(11):1061-1069

Warren-Gash C, Blackburn R, Whitaker H, McMenamin J, Hayward AC (2018) Laboratory-confirmed respiratory infections as triggers for acute myocardial infarction and stroke: a self-controlled case series analysis of national linked datasets from Scotland. Eur Respir J 51(3):1701794

Wege H (1995) Immunopathological aspects of coronavirus infections. Semin Immunopathol 17(2-3):133-148

Wölfel R, Corman VM, Guggemos W, Seilmaier M, Zange S, Müller MA (2020) Virological assessment of hospitalized patients with COVID-2019. Nature 581(7809):465-469

Wong SH, Lui RN, Sung JJ (2020) Covid-19 and the digestive system. J Gastroenterol Hepatol 35(5):744-748

Worldometer (2020) COVID-19 coronavirus pandemic (https://www. worldometers.info/coronavirus/)

World Health Organization (WHO) (2020) Coronavirus disease 2019 (COVID-19) Situation Report - 94 (https://www.who.int/docs/ default-source/coronaviruse/situation-reports/20200423-sitrep94-covid-19.pdf\#: :text=The\%20first $\% 20$ human $\% 20$ cases $\%$ 20of,\%2C\%20in\%20December\%202019)

Wrapp D, Wang N, Corbett KS, Goldsmith JA, Hsieh CL, Abiona O (2020) Cryo-EM structure of the 2019-nCoV spike in the prefusion conformation. Science 367(6483):1260-1263

Wu GF, Perlman S (1999) Macrophage infiltration, but not apoptosis, is correlated with immune-mediated demyelination following murine infection with a neurotropic coronavirus. J Virol 73(10):8771-8780

Wuthrich C, Batson S, Koralnik IJ (2015) Lack of Major Histocompatibility complex class I upregulation and restrictive infection by JC virus hamper detection of neuronsby $\mathrm{T}$ lymphocytes in the central nervous system. J Neuropathol Exp Neurol 74(8):791-803

Xia H, Lazartigues E (2008) Angiotensin-converting enzyme 2 in the brain: properties and future directions. J Neurochem 107(6):1482-1494. https://doi.org/10.1111/j.1471-159.2008.05723.x

Xiang P, Xu XM, Gao LL, Wang HZ, Xiong HF, Li RH (2020) First case of 2019 novel coronavirus disease with Encephalitis. ChinaXiv T202003:00015

Xu H, Zhong L, Deng J, Peng J, Dan H, Zeng X, Li T, Chen Q (2020) High expression of ACE2 receptor of 2019-nCoV on the epithelial cells of oral mucosa. Int J Oral Sci 12:8

Xu J, Zhong S, Liu J, Li L, Li Y, Wu X, Li Z, Deng P, Zhang J, Zhong N, Ding Y, Jiang Y (2005) Detection of severe acute respiratory syndrome coronavirus in the brain: potential role of the chemokine MIG in pathogenesis. Clin Infect Dis 41(8):1089-1096

Xu Z, Shi L, Wang Y, Zhang J, Huang L, Zhang C, Liu S, Zhao P, Liu H, Zhu L, Tai Y, Bai C, Gao T, Song J, Xia P, Dong J, Zhao J, Wang FS (2020) Pathological findings of COVID-19 associated with acute respiratory distress syndrome. Lancet Respir Med 8(4):420-422

Yang J (2020) Prevalence of comorbidities in the novel Wuhan coronavirus (COVID-19) infection: a systematic review and meta-analysis. Int J Infect Dis 94:91-95

Yang P, Gu H, Zhao Z, Wang W, Cao B, Lai C, Yang X, Zhang LY, Duan Y, Zhang S, Chen W, Zhen W, Cai M, Penninger JM, Jiyang C, Wang X (2014) Angiotensin-converting enzyme 2 (ACE2) mediates influenza H7N9 virus-induced acute lung injury. Sci Rep 4:7027 
Yeh EA (2004) Detection of coronavirus in the central nervous system of a child with acute disseminated encephalomyelitis. Pediatrics 113 (1Pt1):e73-6

Yin CH, Wang C, Tang Z, Wen Y, Zhang SW, Wang BE (2004) Clinical analysis of multiple organ dysfunction syndrome in patients suffering from SARS. Zhongguo Wei Zhong Bing Ji Jiu Yi Xue 16(11):646-650

Young GB (2013) Encephalopathy of infection and systemic inflammation. J Clin Neurophysiol 30(5):454-461

Zhang H, Penninger JM, Li Y, Zhong N, Slutsky AS (2020) Angiotensinconverting enzyme 2 (ACE2) as a SARS-CoV-2 receptor: molecular mechanisms and potential therapeutic target. Intensive Care Med 46:586-590

Zhang H (2020) Early lessons from the frontline of the 2019-nCoV outbreak. Lancet 395(10225):687
Zhao H, Shen D, Zhou H, Liu J, Chen S (2020) Guillain-Barre syndrome associated with SARS CoV-2 infection: causality or coincidence? Lancet Neurol 19(5):383-384

Zhao K, Huang J, Dai D, Feng Y, Liu L, Nie S (2020a) Acutemyelitis after SARS-CoV-2 infection: a case report. Published March 18, 2020. Accessed 19 May 2020. https://www.medrxiv.org/content/https:// doi.org/10.1101/2020.03.16.2003510v2

Zhao K, Huang J, Dai D, Feng Y, Liu L, Nie S (2020b) Acute myelitis after SARS-CoV-2 infection: a case report. medRxiv 2020(03):20035105

Zhou F (2020) Clinical course and risk factors for mortality of adult in patients with COVID-19 in Wuhan, China: a retrospective cohort study. Lancet 395(10229):1054-1062

Publisher's Note Springer Nature remains neutral with regard to jurisdictional claims in published maps and institutional affiliations.

\section{Affiliations}

\section{Niraj Kumar Jha ${ }^{1}$ (1) Shreesh Ojha ${ }^{2}$. Saurabh Kumar Jha ${ }^{1} \cdot$ Harish Dureja ${ }^{3}$. Sachin Kumar Singh ${ }^{4}$. Shakti D. Shukla ${ }^{5}$. Dinesh Kumar Chellappan ${ }^{6}$. Gaurav Gupta ${ }^{7}$. Shanu Bhardwaj ${ }^{8} \cdot$ Neeraj Kumar $^{9} \cdot$ Madhan Jeyaraman $^{10}$. Rashmi Jain ${ }^{11}$. Sathish Muthu ${ }^{12}$. Rohan Kar $^{13}$. Dhruv Kumar ${ }^{14}$. Vineet Kumar Goswami ${ }^{15}$. Janne Ruokolainen ${ }^{16}$. Kavindra Kumar Kesari ${ }^{16} \cdot$ Sandeep Kumar Singh ${ }^{17,18} \cdot$ Kamal Dua $^{5,19,20}$}

1 Department of Biotechnology, School of Engineering \& Technology (SET), Sharda University, Greater Noida 201310, UP, India

2 Department of Pharmacology and Therapeutics, College of Medicine and Health Sciences, PO Box - 17666, United Arab Emirates University, Al Ain, UAE

3 Faculty of Pharmaceutical Sciences, Maharshi Dayanand University, Rohtak, India

4 School of Pharmaceutical Sciences, Lovely Professional University, Punjab, India

5 Priority Research Centre for Healthy Lungs, Hunter Medical Research Institute (HMRI), University of Newcastle, New Lambton Heights, Newcastle, NSW 2305, Australia

6 Department of Life Sciences, School of Pharmacy, International Medical University, Bukit Jalil, 57000 Kuala Lumpur, Malaysia

7 School of Pharmacy, Suresh Gyan Vihar University, Jagatpura, Mahal Road, Jaipur, India

8 Department of Biotechnology, HIMT, CCS University, Greater Noida, UP, India

9 Department of Chemistry, University of Delhi, Delhi 110007 , India

10 Department of Orthopaedics, School of Medical Sciences and Research, Sharda University, UP 201310 Greater Noida, India
11 School of Medical Sciences and Research, Sharda University, UP 201310 Greater Noida, India

12 Research Associate, Orthopaedic Research Group, Coimbatore, Tamil Nadu, India

13 Indian Institute of Management Ahmedabad (IIMA), Gujarat 380015, India

14 Amity Institute of Molecular Medicine and Stem Cell Research (AIMMSCR), Amity University Uttar Pradesh, Noida 201313, India

15 Department of Biological Sciences, School of Basic and Applied Sciences, G.D. Goenka University, G.D. Goenka Education City Sohna Gurugram Road Haryana - 122103, India

16 Department of Applied Physics, School of Science, Aalto University, 00076 Espoo, Finland

17 Centre of Biomedical Research, SGPGI Campus, Lucknow 226014, UP, India

18 Indian Scientific Education and Technology Foundation, Lucknow 226002, UP, India

19 Discipline of Pharmacy, Graduate School of Health, University of Technology Sydney, Sydney, NSW 2007, Australia

20 School of Pharmaceutical Sciences, Shoolini University of Biotechnology and Management Sciences, Post box no. 9, Solan, Himachal Pradesh 173229, India 